\title{
O potencial de geração CBM (Coalbed Methane) na jazida Sul Catarinense: 1. Características petrográficas e químicas das camadas de carvão da Formação Rio Bonito, Permiano da Bacia do Paraná The potential of CBM (Coalbed Methane) generation in the South Santa Catarina reserve: 1 . petrographic and chemical characteristics of the coal seams in Rio Bonito Formation, Paraná Basin \\ Priscila dos Santos Lourenzi ${ }^{1 *}$, Wolfgang Kalkreuth ${ }^{2}$
}

\begin{abstract}
RESUMO: Atualmente, o CBM representa uma importante fonte de energia alternativa. A mais importante sucessão sedimentar portadora de carváo no Brasil ocorre na Bacia do Paraná, com as maiores reservas localizadas nas jazidas do RS e de SC. Este trabalho tem por objetivo analisar as características químicas e petrográficas das camadas de carvão de três poços, realizados recentemente na jazida Sul Catarinense (SC) nos municípios de Treviso e Araranguá, com o intuito de avaliar a capacidade de geraçáo de gás metano associado. Foram coletadas amostras de sete camadas de carvão (Barro Branco, Irapuá, A, Bonito Superior, Bonito Inferior, Pré-Bonito Superior e Pré-Bonito Inferior) da Formação Rio Bonito que foram submetidas à análise petrográfica e química. O litotipo carváo fosco bandado $(\mathrm{BD})$ predominou no CBM-SC-2012, e carvão fosco (D), no CBM-SC-2013. Os resultados petrográficos indicaram valores de 0,60 a 1,26 Rrandom (\%), classificando o carvão segundo o rank desde betuminoso alto volátil C até betuminoso médio volátil. A análise de macerais mostra variação na composição das camadas, com predomínio de vitrinita e inertinita. Quanto à análise imediata, as amostras variaram de 34,93 a 65,70\% em peso de cinza. O poder calorífico varia de 1858,0 a $5074,8 \mathrm{cal} / \mathrm{g}$. O conteúdo de carbono varia de 4,15 a 65,81\%, e o enxofre, de 0,22 a $12,43 \%$. De acordo com os parâmetros analisados, as camadas Barro Branco e Irapuá apresentam as condições necessárias para geração e armazenagem de gás natural, enquanto a camada Bonito apresenta baixo potencial devido ao alto conteúdo de matéria mineral.
\end{abstract}

PALAVRAS-CHAVE: Carvão; gás natural; Formação Rio Bonito.

\begin{abstract}
Currently, CBM is an important source of alternative energy in Brazil. The most important coal bearing sedimentary succession occurs in the Paraná Basin, and the largest reserves are located in $R S$ and SC. This work aims to analyze the chemical and petrological characteristics of coal seams from three boreholes, being recently conducted in the South Santa Catarina coalfield, in the areas of Treviso and Ararangua $(S C)$, in order to assess the capacity to generate associated methane gas. Samples of seven coal seams were collected (Barro Branco, Irapuá, seam A, Bonito Superior, Bonito Inferior, Pré-Bonito Superior and Pré-Bonito Inferior) from the Rio Bonito Formation, and were prepared and submitted for petrographic and chemical analysis. The lithotype banded dull (BD) was prevalent in hole CBM-SC-2012, and dull (D) in hole CBMSC-2013. Petrographic results indicated average vitrinite reflectance values from 0.60 to $1.26 \%$ Rrandom, classifying the seams according to rank from high volatile bituminous $C$ to medium volatile bituminous. Maceral analysis showed significant variation in maceral composition, with predominance of vitrinite and inertinite. Results from the proximate analysis showed ash variation from 34.93 to $65.70 \mathrm{wt} \%$, whereas the gross calorific value varied from 1858.0 to $5074.8 \mathrm{callg}$. The carbon content ranged from 4.15 to $65.81 \mathrm{wt} \%$, and sulfur ranged from 0.22 to $12.43 \%$. According to the analyzed parameters, the Barro Branco and Irapuá seams present characteristics suitable for the generation of natural gas, whereas the Bonito seam has a lower gas generation potential because of its high ash content.
\end{abstract}

KEYWORDS: Coal; natural gas; Rio Bonito Formation.

\footnotetext{
${ }^{1}$ Programa de Pós-Graduação em Geociências, Instituto de Geociências, Universidade Federal do Rio Grande do Sul - UFRGS, Porto Alegre (RS), Brasil. E-mail:priscilalourenzi@gmail.com

2Instituto de Geociências, Universidade Federal do Rio Grande do Sul - UFRGS, Porto Alegre(RS),Brasil. E-mail: wolfgang.kalkreuth@ufrgs.br *Autor correspondente

Manuscrito ID 30075. Recebido em: 17/01/2014. Aprovado em: 19/09/2014.
} 


\section{INTRODUÇÃO}

No Brasil, a principal e certamente a mais importante sucessão sedimentar portadora de carvão ocorre na Bacia do Paraná, que é uma vasta bacia intracratônica paleozoica sul-americana, desenvolvida completamente sobre crosta continental e preenchida por rochas sedimentares e vulcânicas, cujas idades variam entre o Ordoviciano e o Cretáceo (Zalánet al. 1990; Milani et al. 2007). As camadas de carvão em questão pertencem à Formação Rio Bonito, que teve sua gênese durante o Eopermiano da Bacia do Paraná, em pântanos associados a um paleoambiente parálico. O rank desses carvôes varia desde sub-betuminoso, na jazida de Candiota (RS), até betuminoso alto volátil A e antracito (em contato com diques vulcânicos), na jazida de Santa Terezinha (RS) e na jazida Sul Catarinense (SC) (Kalkreuth et al. 2010).

Com a diminuição dos recursos mundiais de petróleo e gás natural em reservatórios convencionais, o interesse por outras fontes de energia alternativa, como o metano em camadas de carvão (CBM), vem se intensificando nos últimos anos. Para avaliar o potencial de CBM no Brasil como fonte regional de energia é necessário realizar mais estudos sobre o conteúdo de gás e o rank do carvão em diferentes níveis de profundidade dos possíveis reservatórios, com a finalidade de avaliar a capacidade de geração de metano nas camadas do depósito. O termo CBM (coalbed methane) é a nomenclatura utilizada para se referir ao gás metano gerado e armazenado nas camadas de carvão.

As camadas de carvão da jazida Sul Catarinense são de idade Permiana inferior e ocorrem na Formação Rio Bonito. Este é o depósito de carvão brasileiro mais intensamente explorado nas últimas décadas, com reservas na ordem de 32 bilhóes de toneladas (Informativo Anual da Indústria Carbonífera, 2000). A jazida contém até 10 camadas de carvão, sendo que as camadas Barro Branco, Irapuá e Bonito são as mais importantes economicamente.

Este trabalho tem como objetivo analisar as características químicas e petrográficas das camadas de carvão de três furos de sondagens realizados recentemente na jazida Sul Catarinense, no estado de Santa Catarina, com o intuito de avaliar a capacidade de geração de gás metano associado com as camadas de carvão, com base nas características petrográficas e químicas. Para isso foram coletadas amostras de carvão da Formação Rio Bonito nos três furos de sondagens realizados na jazida Sul Catarinense, que foram submetidas a análises.

\section{Localização da Área de Estudo}

A jazida Sul Catarinense está localizada na margem atlântica do território brasileiro, na parte sudeste do estado de Santa Catarina (Fig. 1). Em planta, a Jazida Sul Catarinense possui forma alongada, formando um arco cuja convexidade aponta para leste. Seus limites sulsudeste estão indeterminados, sendo que sondagens sob lâmina d'água na plataforma continental certamente constatariam a continuidade das camadas em sub-superfície (Aramis et al. 2003).

A porção norte do arco é aquela que tem sido intensamente pesquisada e explorada, apresentando comprimento que ultrapassa os $85 \mathrm{~km}$ e largura variável entre 5 e $20 \mathrm{~km}$ (Fig. 1).

Foram realizados três furos de sondagem (Quadro 1): os dois primeiros estão localizados próximos ao litoral no município de Araranguá (SC), e foram denominados de CBM-SC-2011 e CBM-SC-2012; o terceiro furo está localizado mais ao norte da jazida, no município de Treviso (SC), e foi denominado de CBM-SC-2013 (Fig.2).

\section{Geologia Local}

A área de estudo encontra-se inserida na supersequência Gondwana I, que, segundo Milani (1997), engloba o maior volume sedimentar da Bacia do Paraná, aflorando em uma faixa contínua ao longo do perímetro da sinéclise e exibindo, em subsuperfície, uma espessura total máxima da ordem de 2.500 metros.

Esta unidade registra um ciclo transgressivo-regressivo completo, que reflete uma grande variedade de condiçóes deposicionais sucedendo-se no tempo e evoluindo entre um contexto Neocarbonífero de sedimentação, com marcada influência glacial, até um amplo e árido interior continental, com domínio de campos de dunas eólicas já no início do Mesozoico.

O carvão em estudo pertence ao Membro Siderópolis, da Formação Rio Bonito, que faz parte do Grupo Guatá, da supersequência Gondwana I (Milani 1997). Segundo a interpretação estratigráfica de Kalkreuth et al. (2010), a base da Formação Rio Bonito foi depositada em um trato de sistemas de nível baixo (TSNB), com sedimentos regressivos flúvio-deltáicos marcando a base do Membro Triunfo (Fig. 3A). Acima desses sedimentos foram depositados os sedimentos do trato de sistemas transgressivo (TST), que é marcado por um sistema retrogradacional (estuarinas a marinho raso), o que corresponde litoestratigraficamente ao topo do Membro Triunfo (com poucas, finas e descontínuascamadas de carvão) e ao Membro Paraguaçu (Fig. 3A). Acima desses sedimentos, o trato de sistemas de nível alto é caracterizado por arenitos costeiros regressivos, com camadas de carvão importantes (litoestratigraficamente a base do Membro Siderópolis). A mudança do trato de sistemas de nível alto (TSNA) para o trato de sistemas de nível baixo (TSNB), na parte mediana do Membro 


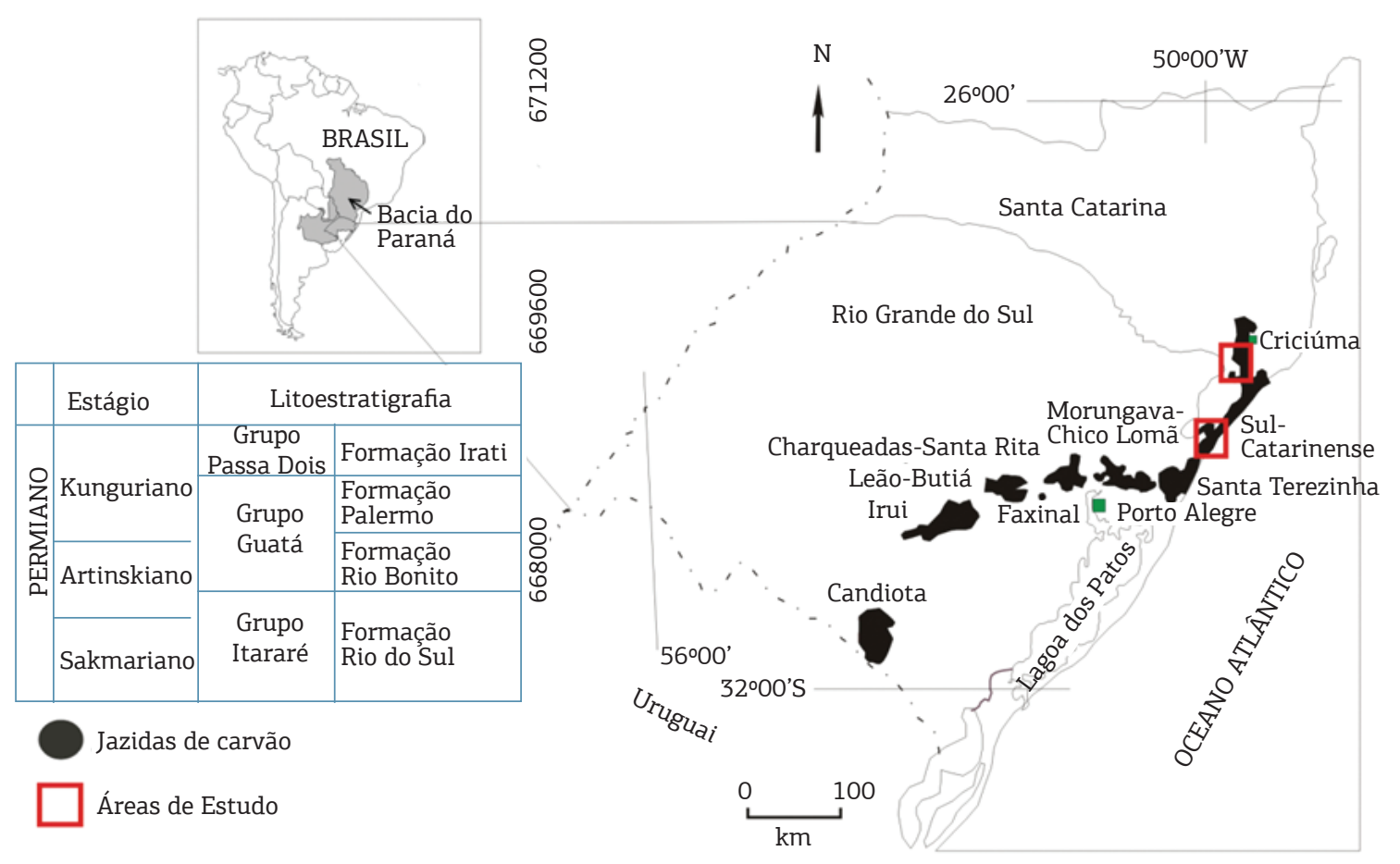

Figura 1. Localização da Bacia do Paraná ressaltando a distribuição das jazidas de carvão nos estados do Rio Grande do Sul e Santa Catarina; no quadro interno destaca-se a Litoestratigrafia, da Formação Rio Bonito. (modificado de Kalkreuth et al., 2003).

Quadro 1. Coordenadas UTM dos poços.

\begin{tabular}{|l|c|c|}
\hline \multirow{2}{*}{ Poço } & \multicolumn{2}{c|}{ Coordenadas UTM } \\
\cline { 2 - 3 } & E & N \\
\hline CBM-SC-2011 & 665226 & 6804697 \\
\hline CBM-SC-2012 & 663901 & 6803741 \\
\hline CBM-SC-2013 & 646061 & 6844225 \\
\hline
\end{tabular}

Siderópolis, é marcada pela entrada da progradação flúviodeltáica de um sistema laguna-barreira (Fig. 3A). No topo do Membro Siderópolis o trato de sistemas transgressivo (TST) é marcado pela mudança do regime de sedimentação progradacional para retrogradacional. O TSNB e a porção basal do TST correspondem às porções médias e superiores do Membro Siderópolis (Fig. 3A), onde as importantes camadas de carvão foram depositadas.Já a porção superior do TST corresponde aos sedimentos marinhos rasos da Formação Palermo (Fig. 3A).

\section{METODOLOGIA}

\section{Amostragem e Preparação}

O primeiro furo (CBM-SC-2011) teve profundidade total de 327,15 m (Fig. 3B). A Formação Rio Bonito encontra-se a partir da profundidade $239 \mathrm{~m}$, onde foram identificadas sete camadas de carvão (Barro Branco, Irapuá, A, Bonito Superior, Bonito Inferior, Pré-Bonito Superior e Pré-Bonito Inferior) e 18 amostras foram coletadas (Tab. 1). O segundo furo (CBM-SC-2012) teve profundidade total de $341 \mathrm{~m}$ (Fig. 3B), e a Formação Rio Bonito encontra-se a partir da profundidade $190,90 \mathrm{~m}$, onde cinco camadas de carvão foram identificadas (Barro Branco, Bonito Superior, Bonito Inferior, Pré-Bonito Superior e Pré-Bonito Inferior) e 21 amostras foram coletadas (Tab. 1). O terceiro furo (CBM-SC-2013) teve profundidade total de 249,30 m (Fig. 3B), e a Formação Rio Bonito encontra-se a partir da profundidade $141,75 \mathrm{~m}$, onde somente três camadas foram identificadas (Barro Branco, Irapuá e Bonito Inferior) e 22 amostras foram coletadas (Fig. 3B). O número das amostras e sua profundidade, bem como a camada a que pertencem, está detalhado na Tab. 1 . 


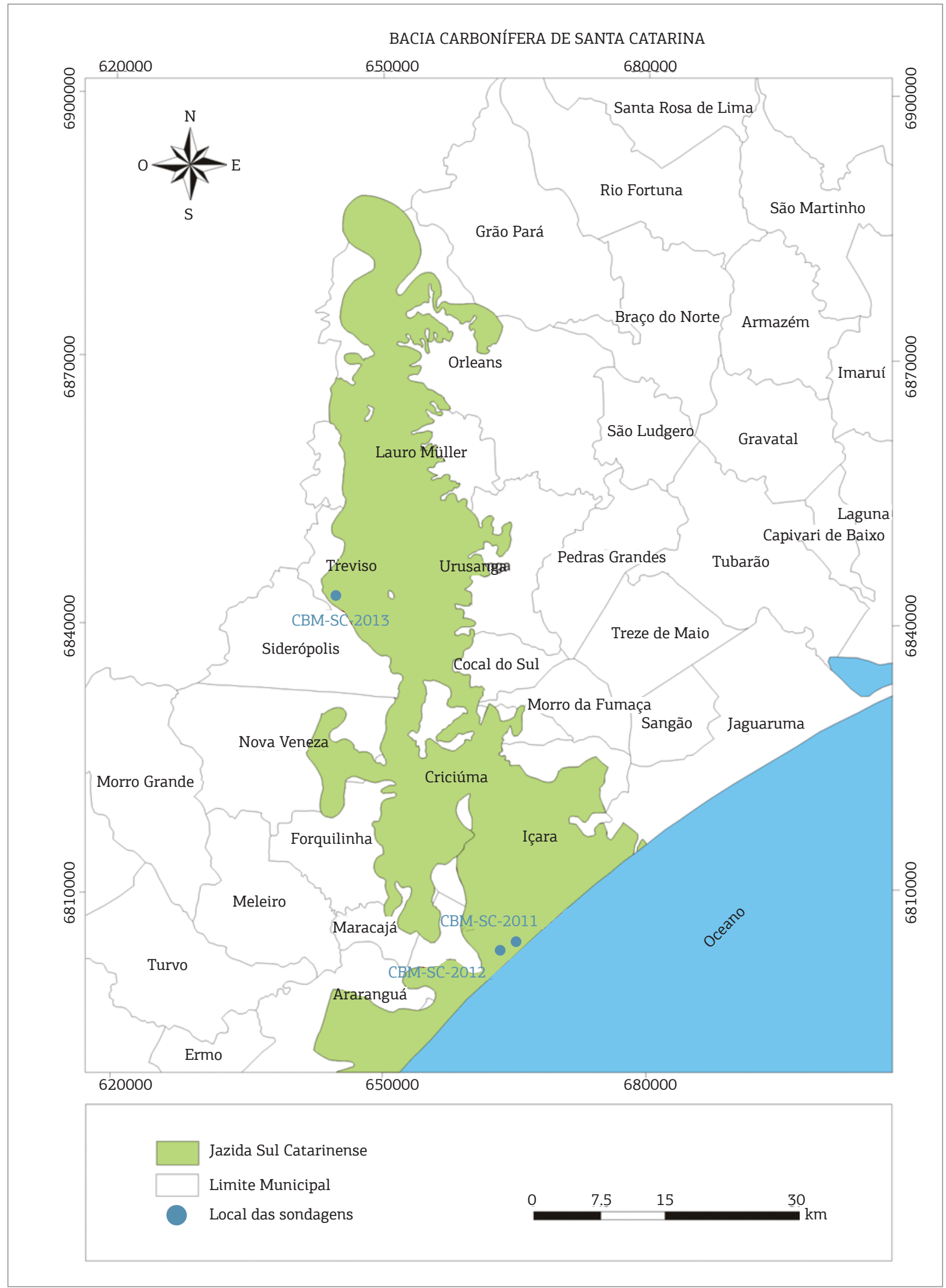

Figura 2. Localização dos três furos de sondagens (CBM-SC-2011, CBM-SC-2012, CBM-SC-2013) na jazida Sul Catarinense (SC). 
A

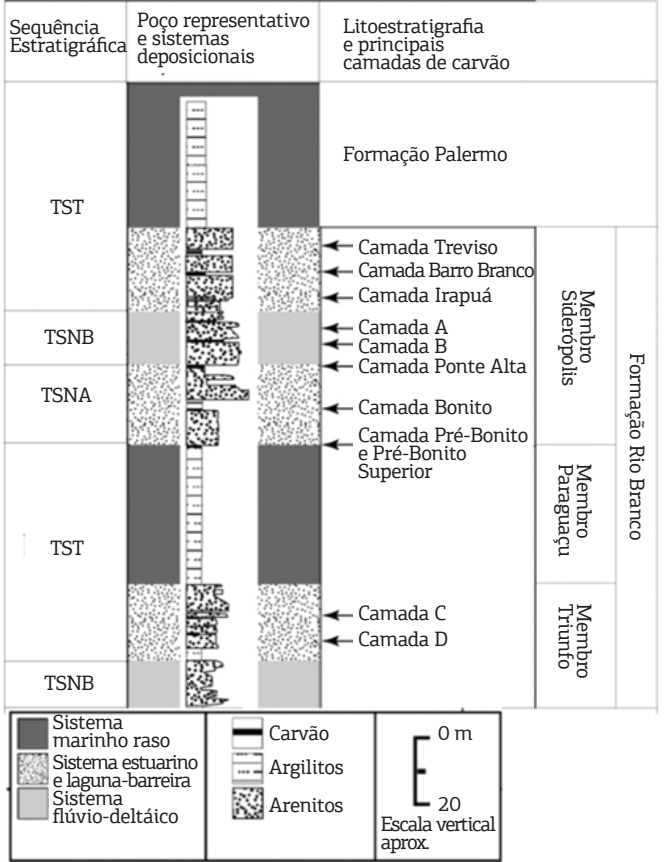

B

CBM-SC-2011

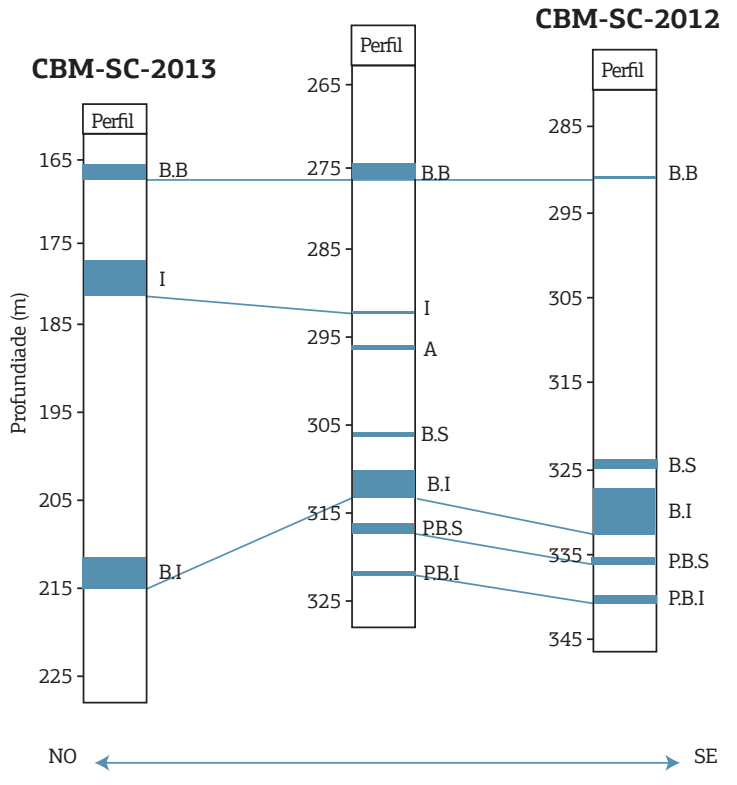

TST: trato de sistemas transgressivo; TSNB: trato de sistemas de nível baixo; TSNA: trato de sistemas de nível alto (Modificado de Kalkreuth et. al. 2010). B.B: Barro Branco; I: Irapuá; A: Camada A; B.S: Bonito Superior; B.I: Bonito Inferior; P.B.S: Pré-Bonito Superior; P.B.I: Pré-Bonito Inferior. Datum: base da camada Barro Branco. Para localização dos furos, ver Fig. 2.

Figura 3. (A) Perfil estratigráfico representativo da jazida Sul Catarinense, mostrando a associação de fácies, sistemas deposicionais e os tratos de sistemas. (B) Perfil esquemático NO-SE correlacionando as camadas de carvão dos três furos de sondagem utilizados.

Tabela 1. Número, profundidade e espessura das amostras e a camada a que pertencem

\begin{tabular}{|c|c|c|c|}
\hline \multicolumn{4}{|c|}{ CBM-SC-2011 } \\
\hline Amostras & Profundidade (m) & Espes. (m) & Camada \\
\hline $11-001$ & $274,54-275,26$ & 0,25 & B.B \\
\hline $11-002$ & $275,26-275,62$ & 0,10 & B.B \\
\hline $11-003$ & $275,62-275,98$ & 0,23 & B.B \\
\hline $11-004$ & $275,98-276,34$ & 0,34 & B.B \\
\hline $11-005$ & $276,34-276,70$ & 0,18 & B.B \\
\hline $11-006$ & $292,60-292,96$ & 0,12 & I \\
\hline $11-007$ & $295,64-296,00$ & 0,36 & A \\
\hline $11-008$ & $305,65-306,01$ & 0,25 & B.S \\
\hline $11-009$ & $306,01-306,37$ & 0,24 & B.S \\
\hline $11-010$ & $310,35-310,71$ & 0,22 & B.I \\
\hline $11-011$ & $310,71-311,07$ & 0,18 & B.I \\
\hline $11-012$ & $311,07-311,43$ & 0,10 & B.I \\
\hline $11-013$ & $311,95-313,03$ & 0,96 & B.I \\
\hline $11-014$ & $313,03-313,75$ & 0,54 & B.I \\
\hline $11-015$ & $313,75-314,11$ & 0,13 & B.I \\
\hline $11-016$ & $316,97-317,69$ & 0,72 & P.B.S \\
\hline $11-017$ & $317,69-318,05$ & 0,30 & P.B.S \\
\hline $11-018$ & $321,13-321,49$ & 0,16 & P.B.I \\
\hline
\end{tabular}


Tabela 1.Continuação

\begin{tabular}{|c|c|c|c|}
\hline \multicolumn{4}{|c|}{ CBM-SC-2012 } \\
\hline Amostras & Profundidade (m) & Espes. (m) & Camada \\
\hline $13-010$ & $292,00-292,36$ & 0,20 & B.B \\
\hline $13-011$ & $324,30-324,66$ & 0,17 & B.S \\
\hline $13-012$ & $324,66-325,02$ & 0,26 & B.S \\
\hline $13-013$ & $327,73-328,09$ & 0,30 & B.I \\
\hline $13-014$ & $328,09-328,46$ & 0,13 & B.I \\
\hline $13-015$ & $328,46-328,83$ & 0,17 & B.I \\
\hline $13-016$ & $328,83-329,20$ & 0,37 & B.I \\
\hline $13-017$ & $329,20-329,56$ & 0,19 & B.I \\
\hline $13-018$ & $329,56-329,93$ & 0,37 & B.I \\
\hline $13-019$ & $329,93-330,29$ & 0,14 & B.I \\
\hline $13-020$ & $330,38-330,73$ & 0,29 & B.I \\
\hline $13-021$ & $330,73-331,09$ & 0,36 & B.I \\
\hline $13-022$ & $331,11-331,47$ & 0,25 & B.I \\
\hline $13-023$ & $331,60-331,97$ & 0,37 & B.I \\
\hline $13-024$ & $331,97-332,33$ & 0,36 & B.I \\
\hline $13-025$ & $335,11-335,47$ & 0,16 & P.B.S \\
\hline $13-026$ & $335,47-335,86$ & 0,39 & P.B.S \\
\hline $13-027$ & $335,86-336,22$ & 0,36 & P.B.S \\
\hline $13-028$ & $336,22-336,57$ & 0,35 & P.B.S \\
\hline $13-029$ & $339,12-339,47$ & 0,35 & P.B.I \\
\hline $13-030$ & $339,47-339,83$ & 0,29 & P.B.I \\
\hline \multicolumn{4}{|c|}{ CBM-SC-2013 } \\
\hline Amostras & Profundidade (m) & Espes. (m) & Camada \\
\hline $13-101$ & $166,14-167,13$ & 0,41 & B.B \\
\hline $13-102$ & $167,13-167,50$ & 0,37 & B.B \\
\hline $13-103$ & $167,50-167,87$ & 0,26 & B.B \\
\hline $13-104$ & $177,19-177,93$ & 0,48 & I \\
\hline $13-105$ & $177,93-178,35$ & 0,42 & I \\
\hline $13-106$ & $178,35-178,70$ & 0,35 & I \\
\hline $13-107$ & $178,70-179,05$ & 0,35 & I \\
\hline $13-108$ & $179,05-179,40$ & 0,35 & I \\
\hline $13-109$ & $179,40-179,75$ & 0,35 & I \\
\hline $13-110$ & $179,75-180,10$ & 0,35 & I \\
\hline $13-111$ & $180,10-180,45$ & 0,35 & I \\
\hline $13-112$ & $180,95-181,30$ & 0,21 & I \\
\hline $13-113$ & $180,95-181,30$ & 0,14 & I \\
\hline $13-114$ & $212,60-212,96$ & 0,18 & B.I \\
\hline $13-115$ & $212,60-212,96$ & 0,18 & B.I \\
\hline $13-116$ & $212,96-213,32$ & 0,36 & B.I \\
\hline $13-117$ & $213,32-213,68$ & 0,36 & B.I \\
\hline $13-118$ & $213,68-214,04$ & 0,36 & B.I \\
\hline $13-119$ & $214,04-214,40$ & 0,36 & B.I \\
\hline $13-120$ & $214,40-214,76$ & 0,36 & B.I \\
\hline $13-121$ & $214,76-215,12$ & 0,15 & B.I \\
\hline $13-122$ & $214,76-215,12$ & 0,21 & B.I \\
\hline
\end{tabular}

B.B: Barro Branco, I: Irapuá, A: Camada A, B.S: Bonito Superior, B.I: Bonito Inferior, P.B.S: Pré-Bonito Superior, P.B.I: Pré-Bonito Inferior 
As amostras de carvão foram preparadas de acordo com o processo que consiste na secagem em estufa com temperatura $\leq 40^{\circ} \mathrm{C}$. Depois, as amostras passaram por um triturador de mandíbulas e homogeneizadas em uma peneira de malha $<4,5 \mathrm{~mm}$. Foram,então, quarteadas e reduzidas a sub-amostras. Uma parte dessas sub-amostras foi pulverizada até a fração $<200$ mesh e, posteriormente, acondicionadas em potes com $20 \mathrm{~g}$, sendo destinadas às análises químicas: análise imediata, análise elementar e poder calorífico superior.

Cerca de $20 \mathrm{~g}$ de amostra com tamanho de grão entre $0,25-0,80 \mathrm{~mm}$ foram utilizadas para o embutimento na confecção de seções polidas em grão, de acordo com as normas estabelecidas pela American Society for Testing and Materials (ASTM D2013/2013M-12, 2012), e foram usadas na análise petrográfica (reflectância da vitrinita e análise de macerais).

\section{Análise Petrológica do carvão}

Descriçâo de litotipos: neste trabalho foi adotada a classificação de litotipos segundo Diessel (1965), conforme detalhado no Quadro 2.

Reflectância da vitrinita (Rrandom \%): o método para a determinação do rank dos carvôes consiste na realização de 100 medidas do poder refletor das partículas de vitrinita em cada amostra. A média aritmética dessas medidas gera o valor do grau de carbonificação (rank) do carvão analisado (ISO-7404/5, 2009).

Análise de macerais: foi realizada de acordo com a norma ISO-7404/3, 2009, e baseia-se na contagem de 500 pontosrealizados em linhas com intervalos pré-definidos. Os resultados obtidos são expressos em Vol.\%.

\section{Análises Químicas}

Análise imediata: compóe-se de quatro diferentes tipos de análises: \% de umidade (ASTM D3173-87), \% de cinzas
(ASTM D3174) e \% de matéria volátil (ASTM D3175). O carbono fixo é umvalor calculado pela soma dos percentuais de umidade, cinza e matéria volátil subtraído de 100. Os resultados obtidos são expressos como \% em peso.

Poder calorifico superior: é determinado em uma Bomba Adiabática Calorimétrica, segundo a norma ASTM D 2015 (1991), e apresenta o calor (cal/g) produzido pela combustão da matéria orgânica.

Análise elementar: é usada para determinar os principais elementos presentes na matéria orgânica do carvão: carbono, hidrogênio, nitrogênio e enxofre, segundo a norma ASTM 5373-93. Os resultados são expressos na forma de $\%$ em peso.

\section{RESULTADOS E DISCUSSÕES}

\section{Descrição de Litotipos}

Após a coleta das amostras de carvão, realizou-se a descrição dos litotipos do carvão nos furos CBM-SC-2012 e CBM-SC-2013. O carvão fosco bandado (BD) é o litotipo dominante no perfil de carvão do primeiro furo, com $53,4 \%$ (Fig. 4), seguido pelo carvão fosco (D), com 33,1\%, carvão bandado (BC), com 11,4\%, bandado brilhante (BB), com $1,4 \%$, e brilhante (B), com somente $0,7 \%$, e apresenta poucas lâminas de pirita ao longo do perfil. Em geral, o litotipo fosco (D) aumenta em direção à base do perfil.

No furo CBM-SC-2013 (Fig. 5), o litotipo dominante é o carvão fosco (D), com 51,9\%, seguido do carvão fosco bandado (BD), com $31,1 \%$, carvão bandado (BC), com $14,7 \%$, bandado brilhante (BB), com 2,1\%, e brilhante (B), com somente $0,2 \%$. As camadas de carvão frequentemente apresentam lâminas de pirita e algumas fraturas preenchidas por carbonato.

Quadro 2. Classificação dos litotipos (Stopes 1919) e (Diessel 1965)

\begin{tabular}{|l|c|c|}
\hline ICCP-Stopes & Diessel (1965) & Descrição \\
\hline Vitrênio & Brilhante (B) & $\begin{array}{c}\text { Brilho vítreo a subvítreo, fratura conchoidal; frágil; até 10\% de } \\
\text { bandas de carvão fosco. }\end{array}$ \\
\hline \multirow{2}{*}{ Clarênio } & Bandado Brilhante (BB) & $\begin{array}{c}\text { Brilhante, com bandas de carvão fosco que podem variar entre } \\
10 \text { e } 40 \% .\end{array}$ \\
\hline \multirow{2}{*}{ Durênio } & Carvão Bandado (BC) & Bandas de carvão brilhante e fosco que variam entre 40 e 60\%. \\
\hline Carvão Fosco Bandado (BD) & Predomínio de carvão fosco com bandas de carvão brilhante em entre 10 e 40\%. \\
\hline pusênio & Carvão Fosco (D) & Fosco e não fraturado, podendo conter até 10\% de carvão \\
brilhante.
\end{tabular}




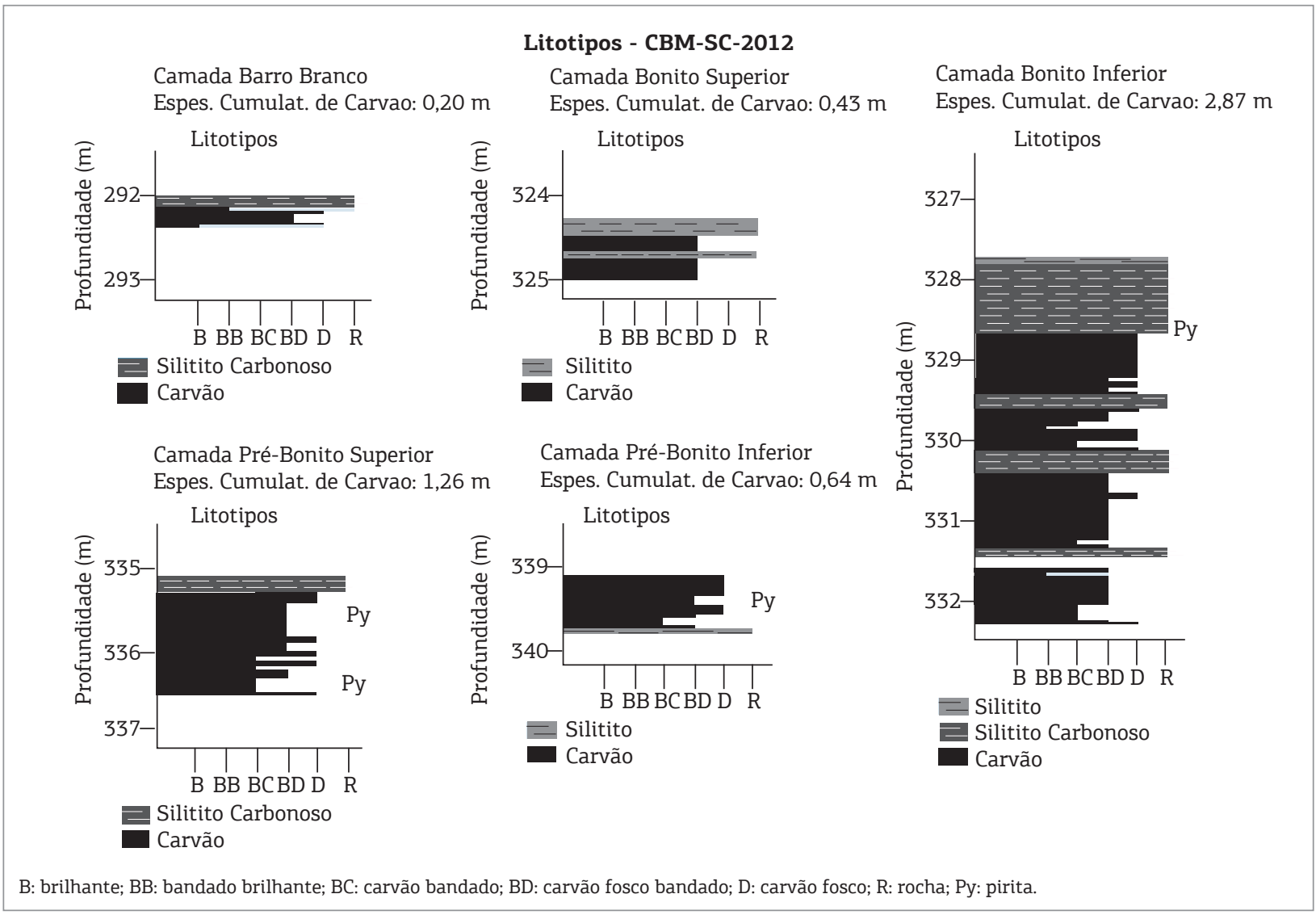

Figura 4. Descrição dos litotipos por camada no furo CBM-SC-2012

\section{Litotipos - CBM-SC-2013}

Camada Barro Branco Camada Irapuá Camada Bonito Inferior

Espessura Cumulativa de Carvao: 1,04 m Espessura Cumulativa de Carvao: 3 m Espessura Cumulativa de Carvao: 2,31 m
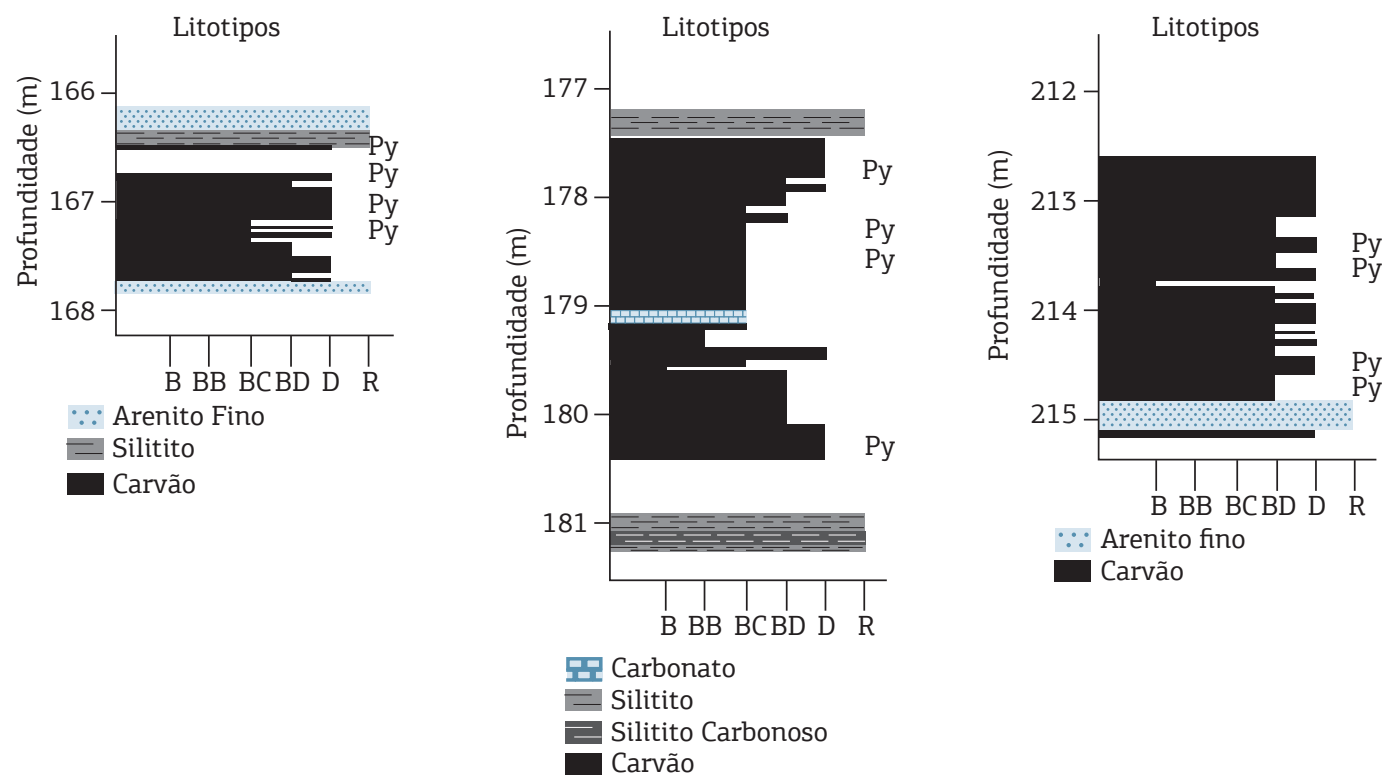

B - brilhante; BB - bandado brilhante; BC - carvão bandado; BD - carvão fosco bandado; D - carvão fosco; R - rocha; Py: pirita.

Figura 5. Descrição dos litotipos por camada no furo CBM-SC-2013 
Segundo Marchioni \& Kalkreuth (1991), estudos em carvôes betuminosos têm mostrado que o conteúdo de vitrinita tende a diminuir, e os conteúdos de inertinita e matéria mineral tendem a aumentar com a diminuição dos componentes brilhosos. Isso pode ser observado na camada Bonito em ambos os furos, onde há enriquecimento de carvão fosco em direção à base da camada, que pode estar relacionado com o alto teor de inertinita e matéria mineral observado na petrografia.

\section{Reflectância da Vitrinita}

Os resultados mostrados na Tab. 2 revelam, para o furo CBM-SC-2011, variação entre 0,60 e 0,87 Rrandom (\%) nas amostras individuais. Já nos valores médios por camada, as camadas Irapuá e A apresentaram valores relativamente baixos se comparadas com os valores obtidos nas demais. Os valores de reflectância da vitrinita obtidos por camada indicam um rank betuminoso alto volátil $\mathrm{C}$ para a camada Irapuá, betuminoso alto volátil $\mathrm{B}$ para a camada $\mathrm{A}$, e betuminoso alto volátil A para as camadas Barro Branco, Bonito Superior, Bonito Inferior, Pré-Bonito Superior e Pré-Bonito Inferior.

As amostras do furo CBM-SC-2012 apresentaram variação entre 0,82 e 0,95 Rrandom (\%) (Tab. 2). Os valores médios por camada variam de 0,84 a 0,88 Rrandom (\%), indicando um rank betuminoso alto volátil A para todas as camadas de carvão encontradas.
As amostras do furo CBM-SC-2013 tiveram variação entre 0,98 e 1,34 Rrandom (\%) (Tab. 2). Os valores médios por camada variaram de 1,00 a 1,26 Rrandom (\%). Os valores médios obtidos por camada indicam um rank betuminoso alto volátil A para a camada Barro Branco, e betuminoso médio volátil para as camadas Irapuá e Bonito Inferior. O aumento nos valores da reflectância da vitrinita das camadas Irapuá e Bonito Inferior neste último poço sugere a presença de intrusóes ígneas nas proximidades das camadas de carvão estudadas, pois a diferença de profundidade entre as camadas não é o suficiente para explicar o aumento do rank entre a camada Barro Branco e as camadas Irapuá e Bonito Inferior. Segundo Filho et al. (2008), o efeito de uma intrusão na encaixante é equivalente à espessura do corpo intrusivo; no caso de intrusôes múltiplas, supóe-se que o efeito possa ser potencializado. Esse processo pode variar em suas dimensôes, em função da profundidade da intrusão, sendo que o calor transmitido é maior quanto maior for a profundidade. Estudos recentes (Levandowski 2013) na jazida de ChicoLomã (RS) mostraram que o efeito das rochas ígneas sobre o carvão pode alcançar até o dobro da espessura da intrusão, afetando as camadas de carvão acima e abaixo da intrusão.

$\mathrm{Na}$ Figura 6 é possível observar que os valores de reflectância da vitrinita obtidos no furo CBM-SC-2012 não mostraram nenhuma relação visível com o conteúdo de cinzas e

Tabela 2. Resultados da reflectância da vitrinita das camadas de carvão analisadas.

\begin{tabular}{|c|c|c|c|}
\hline \multicolumn{4}{|c|}{ CBM-SC-2011 } \\
\hline Amostra/ Camada & $\operatorname{Rr}(\%)$ & $\operatorname{Rr}(\%)$ médio & Classif. \\
\hline 11-001 / B.B & 0,83 & \multirow{5}{*}{0,79} & \multirow{5}{*}{ BAV A } \\
\hline 11-002 / B.B & 0,73 & & \\
\hline 11-003 / B.B & 0,80 & & \\
\hline 11-004 / B.B & 0,80 & & \\
\hline 11-005 / B.B & 0,79 & & \\
\hline $11-006$ / I & 0,60 & 0,60 & BAV C \\
\hline $11-007$ / A & 0,74 & 0,74 & BAV B \\
\hline 11-008 / B.S & 0,82 & \multirow{2}{*}{0,85} & \multirow{2}{*}{ BAV A } \\
\hline 11-009 / B.S & 0,87 & & \\
\hline 11-010 / B.I & 0,82 & \multirow{6}{*}{0,85} & \multirow{6}{*}{ BAV A } \\
\hline 11-011 / B.I & 0,86 & & \\
\hline 11-012 / B.I & 0,85 & & \\
\hline 11-013 / B.I & 0,87 & & \\
\hline 11-014 / B.I & 0,81 & & \\
\hline 11-015 / B.I & 0,87 & & \\
\hline 11-016 / P.B.S & 0,83 & \multirow{2}{*}{0,85} & \multirow{2}{*}{ BAV A } \\
\hline 11-017 / P.B.S & 0,86 & & \\
\hline 11-018 / P.B.I & 0,86 & 0,86 & BAV A \\
\hline
\end{tabular}


Tabela 2. Continuação

\begin{tabular}{|c|c|c|c|}
\hline \multicolumn{4}{|c|}{ CBM-SC-2012 } \\
\hline Amostra/ Camada & $\operatorname{Rr}(\%)$ & Rr (\%) médio & Classif. \\
\hline 13-010 / B.B & 0,87 & 0,87 & BAV A \\
\hline 13-011 / B.S & 0,88 & \multirow{2}{*}{0,91} & \multirow{2}{*}{ BAV A } \\
\hline 13-012 / B.S & 0,93 & & \\
\hline 13-013 / B.I & 0,91 & \multirow{12}{*}{0,88} & \multirow{12}{*}{ BAV A } \\
\hline 13-014 / B.I & - & & \\
\hline 13-015 / B.I & 0,95 & & \\
\hline 13-016 / B.I & 0,90 & & \\
\hline 13-017 / B.I & 0,95 & & \\
\hline 13-018 / B.I & 0,89 & & \\
\hline 13-019 / B.I & 0,89 & & \\
\hline 13-020 / B.I & 0,89 & & \\
\hline 13-021 / B.I & 0,85 & & \\
\hline 13-022 / B.I & 0,84 & & \\
\hline 13-023 / B.I & 0,82 & & \\
\hline 13-024 / B.I & 0,82 & & \\
\hline 13-025 / P.B.S & 0,88 & \multirow{4}{*}{0,86} & \multirow{4}{*}{ BAV A } \\
\hline 13-026 / P.B.S & 0,84 & & \\
\hline 13-027 / P.B.S & 0,85 & & \\
\hline 13-028 / P.B.S & 0,86 & & \\
\hline 13-029 / P.B.I & 0,84 & \multirow{2}{*}{0,84} & \multirow{2}{*}{ BAV A } \\
\hline 13-030 / P.B.I & 0,85 & & \\
\hline \multicolumn{4}{|c|}{ CBM-SC-2013 } \\
\hline Amostra/ Camada & $\mathbf{R r}(\%)$ & $\operatorname{Rr}(\%)$ médio & Classif. \\
\hline 13-101 / B.B & 1,02 & \multirow{3}{*}{1,00} & \multirow{3}{*}{ BAV A } \\
\hline 13-102 / B.B & 0,99 & & \\
\hline 13-103 / B.B & 0,98 & & \\
\hline $13-104 / I$ & 1,17 & \multirow{10}{*}{1,18} & \multirow{10}{*}{ BMV } \\
\hline 13-105 / I & 1,23 & & \\
\hline $13-106$ / I & 1,19 & & \\
\hline 13-107 / I & 1,21 & & \\
\hline $13-108$ / I & 1,23 & & \\
\hline $13-109$ / I & 1,18 & & \\
\hline $13-110$ / I & 1,25 & & \\
\hline $13-111 / \mathrm{I}$ & 1,19 & & \\
\hline $13-112$ / I & 1,03 & & \\
\hline $13-113$ / I & 1,09 & & \\
\hline 13-114 / B.I & 1,25 & \multirow{9}{*}{1,26} & \multirow{9}{*}{ BMV } \\
\hline 13-115 / B.I & 1,25 & & \\
\hline 13-116 / B.I & 1,19 & & \\
\hline 13-117 / B.I & 1,32 & & \\
\hline 13-118 / B.I & 1,34 & & \\
\hline 13-119 / B.I & 1,28 & & \\
\hline 13-120 / B.I & 1,26 & & \\
\hline 13-121 / B.I & 1,19 & & \\
\hline 13-122 / B.I & 1,23 & & \\
\hline
\end{tabular}

$\operatorname{Rr}(\%)$ : Rrandom (\%); Rr (\%) médio: Rrandom (\%) por camada; BAV A: Betuminoso alto volátil A; BAV B: Betuminoso alto volátil B; BAV C: Betuminoso alto volátil C; BMV: Betuminoso médio volátil 
com o aumento da profundidade. Os furos CBM-SC-2011 e CBM-SC-2013 mostram pequeno aumento nos valores de Rrandom (\%) conforme aumenta a profundidade, com exceção das camadas Irapuá e A do primeiro furo que, por apresentarem alto conteúdo de matéria mineral (alto teor de cinzas), apresentam um valor de reflectância relativamente mais baixo. No furo CBM-SC-2013 é possível observar claramente a variaçấo dos valores de reflectância dentro da camada Irapuá: conforme aumenta o conteúdo de cinzas, a reflectância diminui. Essas observaçóes confirmam estudos feitos por Goodarzi et al. (1993), que mostram a significativa diminuição nos valores de reflectância da vitrinita em intervalos ricos em matéria mineral.

Os valores relativamente baixos de reflectância da vitrinita das camadas Irapuá e A no furo CBM-SC-2011 podem ser explicados também de acordo com Leckie et al. (1988). Os autores demonstram que os valores baixos de reflectância da vitrinita são influenciados pela espessura da camada de carvão, pois, quanto mais espessa a camada, maior o tempo em que o calor permanece em seu interior, o que aumenta o rank. Já em camadas mais finas, o calor passaria mais rápido pela camada e, com isso, o carvão náo atingiria o grau de carbonificaçáo que camadas mais espessas atingem.

\section{Análise de Macerais}

A composição petrográfica, sem contar a matéria mineral $($ vitrinita + liptinita + inertinita $=100 \%)$ das amostras dos três furos, é altamente variável. No furo CBM-SC-2011 a vitrinita varia de 19,2 até $84,4 \%$ (Tab. 3), sendo o menor valor encontrado na camada Bonito Inferior, e o maior valor na camada Barro Branco. A liptinita varia de 0 até 25,3\%; a camada Barro Branco apresentou o menor valor, e a camada Bonito Inferior, o maior. A inertinita varia de 13 até 55,5\%, sendo que o menor valor foi encontrado na camada PréBonito Inferior, e o maior valor, na camada Bonito Inferior. Pode-se dizer que há predominância de vitrinita e inertinita em relação à liptinita nas amostras deste furo.

No furo CBM-SC-2012 a vitrinita varia de 6,7até 89,8\% (Tab. 3), sendo que o menor valor foi encontrado nas amostras da camada Bonito Inferior, e o maior valor, na camada Barro Branco. A liptinita varia de 0 até $36,2 \%$, sendo que os dois extremos foram encontrados nas amostras da camada Bonito Inferior. A inertinita varia de 8,0 até $93,3 \%$, sendo que o menor valor foi encontrado na camada Barro Branco, e o maior valor, na camada Bonito Inferior.

No furo CBM-SC-2013 a vitrinita varia de 1,5\%, na camada Bonito Inferior, até 75,1\% na camada Irapuá (Tab. 3). A liptinita só foi encontrada em quantidades muito pequenas $(0,3$ até 2,5\%) na camada Barro Branco. A ausência de liptinita nas outras camadas pode ser explicada pelo alto valor da reflectância da vitrinita encontrado nas camadas Irapuá e Bonito Inferior. Segundo Mastalerz et al. (2009), a ausência de macerais do grupo da liptinita pode indicar que a temperatura da possível intrusão próxima às camadas de carvão deste furo

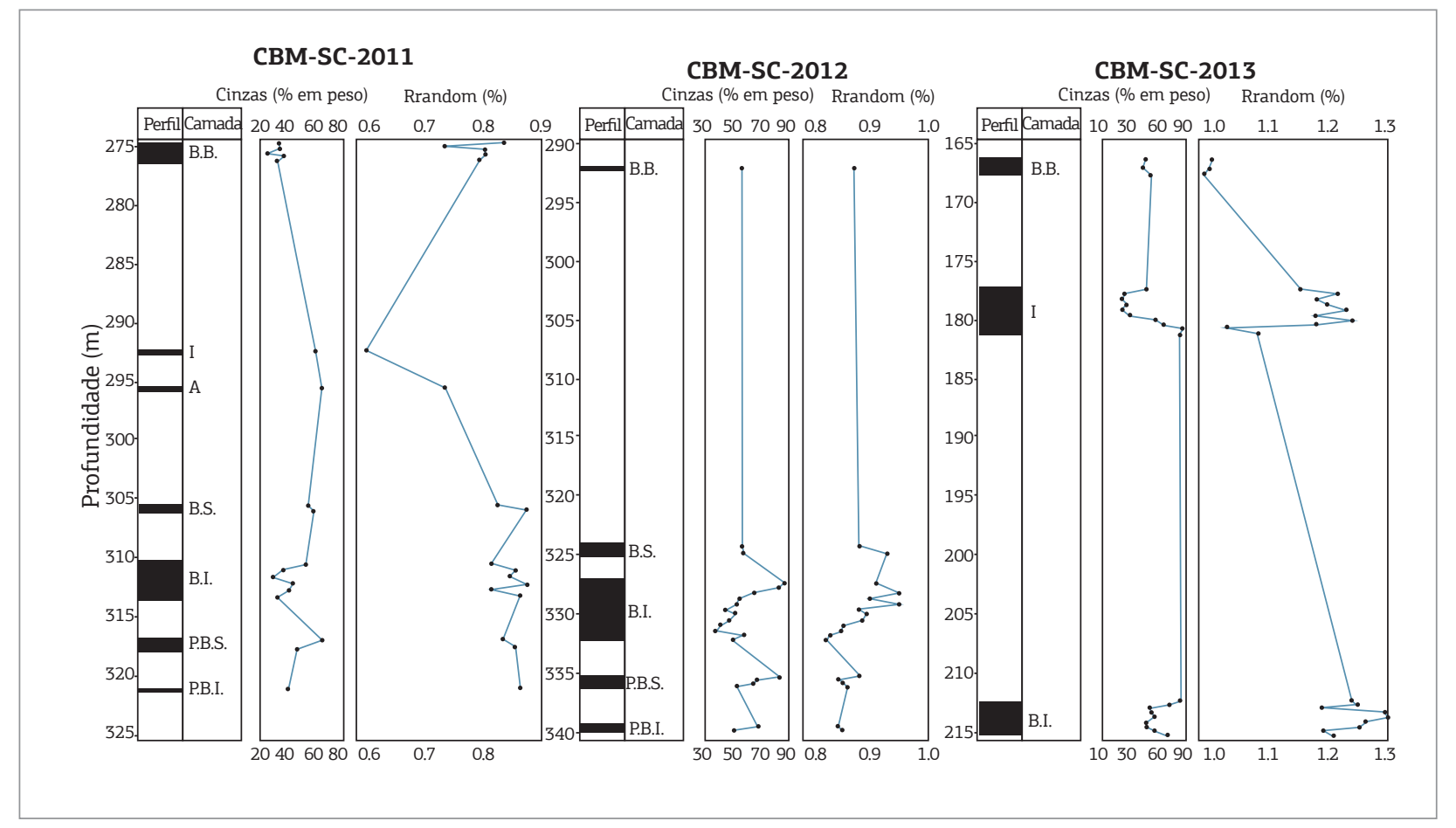

Figura 6. Perfil esquemático mostrando a variação do conteúdo de cinzas e dos valores da reflectância da vitrinita dentro das camadas de carvão. 
Carvão da jazida Sul Catarinense e seu potencial CBM

Tabela 3. Resultados da análise de macerais mostrando a composição maceral e mineral e macerais recalculados (sem matéria mineral) por amostra e por camada total.

\begin{tabular}{|c|c|c|c|c|c|c|c|c|}
\hline \multicolumn{9}{|c|}{ CBM-SC-2011 } \\
\hline Amostra/ Camada & Esp.(m) & \multicolumn{2}{|c|}{ Vitrinita } & \multicolumn{2}{|c|}{ Liptinita } & \multicolumn{2}{|c|}{ Inertinita } & M.M. \\
\hline & & Total & S/MM & Total & S/MM & Total & S/MM & Total \\
\hline 11-001 / B.B & 0,25 & 66,0 & 84,4 & 0,4 & 0,5 & 11,8 & 15,1 & 21,8 \\
\hline 11-002 / B.B & 0,10 & 53,6 & 78,6 & 0,0 & 0,0 & 14,6 & 21,4 & 31,8 \\
\hline 11-003 / B.B & 0,23 & 58,6 & 65,1 & 3,8 & 4,2 & 27,6 & 30,7 & 10,0 \\
\hline 11-004 / B.B & 0,34 & 41,0 & 49,8 & 7,4 & 9,0 & 34,0 & 41,3 & 17,6 \\
\hline 11-005 / B.B & 0,18 & 32,4 & 42,3 & 10,8 & 14,1 & 33,4 & 43,6 & 23,4 \\
\hline B.B - Total & 1,10 & 50,1 & 62,2 & 5,4 & 6,1 & 25,8 & 31,7 & 19,2 \\
\hline $11-006$ / I & 0,12 & 29,2 & 50,7 & 7,8 & 13,5 & 20,6 & 35,8 & 42,4 \\
\hline $11-007$ / A & 0,36 & 20,6 & 36,4 & 6,0 & 10,6 & 30,0 & 53,0 & 43,4 \\
\hline 11-008 / B.S & 0,25 & 18,8 & 32,1 & 8,0 & 13,7 & 31,8 & 54,3 & 41,4 \\
\hline 11-009 / B.S & 0,24 & 19,2 & 32,2 & 14,6 & 24,5 & 25,8 & 43,3 & 40,4 \\
\hline B.S - Total & 0,49 & 19,0 & 32,1 & 11,2 & 19,0 & 28,9 & 48,9 & 40,9 \\
\hline 11-010 / B.I & 0,22 & 14,0 & 19,2 & 18,4 & 25,3 & 40,4 & 55,5 & 27,2 \\
\hline 11-011 / B.I & 0,18 & 31,8 & 39,8 & 12,2 & 15,3 & 36,0 & 45,0 & 20,0 \\
\hline 11-012 / B.I & 0,10 & 47,2 & 50,8 & 14,8 & 15,9 & 31,0 & 33,3 & 7,0 \\
\hline 11-013 / B.I & 0,96 & 21,2 & 26,6 & 16,0 & 20,1 & 42,4 & 53,3 & 20,4 \\
\hline 11-014 / B.I & 0,54 & 43,0 & 49,4 & 13,6 & 15,6 & 30,4 & 34,9 & 13,0 \\
\hline 11-015 / B.I & 0,13 & 60,8 & 74,9 & 4,6 & 5,7 & 15,8 & 19,5 & 18,8 \\
\hline B.I - Total & 2,13 & 30,5 & 36,8 & 14,6 & 18,0 & 36,5 & 45,2 & 18,5 \\
\hline 11-016 / P.B.S & 0,72 & 17,8 & 31,9 & 13,6 & 24,4 & 24,4 & 43,7 & 44,2 \\
\hline 11-017 / P.B.S & 0,30 & 45,4 & 61,2 & 8,6 & 11,6 & 20,2 & 27,2 & 25,8 \\
\hline P.B.S - Total & 1,02 & 25,9 & 40,5 & 12,1 & 20,6 & 23,2 & 38,9 & 38,8 \\
\hline 11-018 / P.B.I & 0,16 & 66,0 & 72,7 & 13,0 & 14,3 & 11,8 & 13,0 & 9,2 \\
\hline \multicolumn{9}{|c|}{ CBM-SC-2012 } \\
\hline Amostra/ Camada & Esp.(m) & \multicolumn{2}{|c|}{ Vitrinita } & \multicolumn{2}{|c|}{ Liptinita } & \multicolumn{2}{|c|}{ Inertinita } & M.M. \\
\hline & & Total & S/MM & Total & S/MM & Total & S/MM & Total \\
\hline 13-010 / B.B & 0,20 & 65,4 & 89,8 & 1,6 & 2,2 & 5,8 & 8,0 & 27,2 \\
\hline 13-011 / B.S & 0,17 & 25,8 & 48,0 & 11,0 & 20,4 & 17,0 & 31,6 & 46,2 \\
\hline 13-012 / B.S & 0,26 & 17,2 & 34,0 & 9,6 & 19,0 & 23,8 & 47,0 & 49,4 \\
\hline B.S - Total & 0,43 & 20,6 & 39,5 & 10,2 & 19,6 & 21,1 & 40,9 & 48,1 \\
\hline 13-013 / B.I & 0,30 & 0,4 & 8,7 & 0,0 & 0,0 & 4,2 & 91,3 & 95,4 \\
\hline 13-014 / B.I & 0,13 & 0,4 & 6,7 & 0,0 & 0,0 & 5,6 & 93,3 & 94,0 \\
\hline 13-015 / B.I & 0,17 & 2,2 & 8,0 & 10,0 & 36,2 & 15,4 & 55,8 & 72,4 \\
\hline 13-016 / B.I & 0,37 & 4,2 & 10,0 & 14,8 & 35,4 & 22,8 & 54,6 & 58,2 \\
\hline 13-017 / B.I & 0,19 & 19,0 & 39,3 & 10,4 & 21,5 & 19,0 & 39,2 & 51,6 \\
\hline 13-018 / B.I & 0,37 & 26,6 & 43,8 & 8,4 & 13,8 & 25,8 & 42,4 & 39,2 \\
\hline 13-019 / B.I & 0,14 & 43,0 & 66,4 & 7,6 & 11,7 & 14,2 & 21,9 & 35,2 \\
\hline 13-020 / B.I & 0,29 & 6,8 & 15,1 & 13,4 & 29,6 & 25,0 & 55,3 & 54,8 \\
\hline 13-021 / B.I & 0,36 & 15,8 & 22,0 & 21,6 & 30,2 & 34,2 & 47,8 & 28,4 \\
\hline 13-022 / B.I & 0,25 & 26,4 & 40,6 & 13,8 & 21,2 & 24,8 & 38,2 & 35,0 \\
\hline 13-023 / B.I & 0,37 & 18,8 & 45,6 & 7,4 & 18,0 & 15,0 & 36,4 & 58,8 \\
\hline 13-024 / B.I & 0,36 & 43,2 & 77,1 & 4,0 & 7,2 & 8,8 & 15,7 & 44,0 \\
\hline B.I - Total & 2,87 & 20,3 & 37,9 & 11,4 & 21,3 & 21,8 & 40,7 & 46,5 \\
\hline 13-025 / P.B.S & 0,16 & 0,6 & 15,0 & 0,6 & 15,0 & 2,8 & 70,0 & 96,0 \\
\hline
\end{tabular}


Priscila dos Santos Lourenzi et al.

Tabela 3. Continuação

\begin{tabular}{|c|c|c|c|c|c|c|c|c|}
\hline \multicolumn{9}{|c|}{ CBM-SC-2012 } \\
\hline \multirow[t]{2}{*}{ Amostra/ Camada } & \multirow[t]{2}{*}{ Esp.(m) } & \multicolumn{2}{|c|}{ Vitrinita } & \multicolumn{2}{|c|}{ Liptinita } & \multicolumn{2}{|c|}{ Inertinita } & \multirow{2}{*}{$\begin{array}{l}\text { M.M. } \\
\text { Total }\end{array}$} \\
\hline & & Total & S/MM & Total & S/MM & Total & S/MM & \\
\hline 13-026 / P.B.S & 0,39 & 12,0 & 41,1 & 7,2 & 24,7 & 10,0 & 34,2 & 70,8 \\
\hline 13-027 / P.B.S & 0,36 & 17,6 & 48,4 & 6,2 & 17,0 & 12,6 & 34,6 & 63,6 \\
\hline 13-028 / P.B.S & 0,35 & 21,4 & 59,1 & 5,0 & 13,8 & 9,8 & 27,1 & 63,8 \\
\hline P.B.S -Total & 1,26 & 14,8 & 44,9 & 5,5 & 18,2 & 9,8 & 36,9 & 70,0 \\
\hline 13-029 / P.B.I & 0,35 & 5,6 & 20,6 & 4,2 & 15,4 & 17,4 & 64,0 & 72,8 \\
\hline 13-030 / P.B.I & 0,29 & 40,8 & 70,6 & 10,2 & 17,6 & 6,8 & 11,8 & 42,2 \\
\hline P.B.I - Total & 0,64 & 21,6 & 43,2 & 6,9 & 16,4 & 12,6 & 40,3 & 58,9 \\
\hline \multicolumn{9}{|c|}{ CBM-SC-2013 } \\
\hline Amostra/ Camada & Esp.(m) & \multicolumn{2}{|c|}{ Vitrinita } & \multicolumn{2}{|c|}{ Liptinita } & \multicolumn{2}{|c|}{ Inertinita } & M.M. \\
\hline & & Total & S/MM & Total & S/MM & Total & $\mathrm{S} / \mathrm{MM}$ & Total \\
\hline 13-101 / B.B & 0,41 & 47,8 & 65,7 & 1,8 & 2,5 & 23,2 & 31,9 & 27,2 \\
\hline 13-102 / B.B & 0,37 & 37,2 & 57,2 & 0,8 & 1,2 & 27,0 & 41,5 & 35,0 \\
\hline 13-103 / B.B & 0,26 & 28,0 & 40,8 & 0,2 & 0,3 & 40,4 & 58,9 & 22,4 \\
\hline B.B - Total & 1,04 & 39,1 & 56,4 & 1,0 & 1,5 & 28,9 & 42,1 & 28,8 \\
\hline $13-104$ / I & 0,48 & 25,4 & 38,7 & 0,0 & 0,0 & 40,2 & 61,3 & 34,4 \\
\hline $13-105$ / I & 0,42 & 55,6 & 67,3 & 0,0 & 0,0 & 27,0 & 32,7 & 17,4 \\
\hline $13-106 / \mathrm{I}$ & 0,35 & 54,4 & 65,1 & 0,0 & 0,0 & 29,2 & 34,9 & 16,4 \\
\hline $13-107$ / I & 0,35 & 48,6 & 59,3 & 0,0 & 0,0 & 33,4 & 40,7 & 18,0 \\
\hline $13-108$ / I & 0,35 & 63,8 & 75,1 & 0,0 & 0,0 & 21,2 & 24,9 & 15,0 \\
\hline $13-109$ / I & 0,35 & 52,2 & 66,9 & 0,0 & 0,0 & 25,8 & 33,1 & 22,0 \\
\hline $13-110 / \mathrm{I}$ & 0,35 & 27,2 & 51,5 & 0,0 & 0,0 & 25,6 & 48,5 & 47,2 \\
\hline $13-111 / \mathrm{I}$ & 0,35 & 15,8 & 44,4 & 0,0 & 0,0 & 19,8 & 55,6 & 64,4 \\
\hline $13-112$ / I & 0,21 & 3,0 & 48,4 & 0,0 & 0,0 & 3,2 & 51,6 & 93,8 \\
\hline $13-113 / \mathrm{I}$ & 0,14 & 0,2 & 3,7 & 0,0 & 0,0 & 5,2 & 96,3 & 94,6 \\
\hline I -Total & 3,00 & 42,6 & 59,6 & 0,0 & 0,0 & 28,8 & 40,4 & 28,6 \\
\hline 13-114 / B.I & 0,18 & 0,2 & 1,5 & 0,0 & 0,0 & 13,4 & 98,5 & 86,4 \\
\hline 13-115 / B.I & 0,18 & 3,0 & 10,8 & 0,0 & 0,0 & 24,8 & 89,2 & 72,2 \\
\hline 13-116 / B.I & 0,36 & 20,8 & 43,2 & 0,0 & 0,0 & 27,4 & 56,8 & 51,8 \\
\hline 13-117 / B.I & 0,36 & 7,2 & 17,8 & 0,0 & 0,0 & 33,2 & 82,2 & 59,6 \\
\hline 13-118 / B.I & 0,36 & 32,4 & 56,8 & 0,0 & 0,0 & 24,6 & 43,2 & 43,0 \\
\hline 13-119 / B.I & 0,36 & 18,4 & 38,8 & 0,0 & 0,0 & 29,0 & 61,2 & 52,6 \\
\hline 13-120 / B.I & 0,36 & 23,6 & 43,5 & 0,0 & 0,0 & 30,6 & 56,5 & 45,8 \\
\hline 13-121 / B.I & 0,15 & 16,0 & 56,7 & 0,0 & 0,0 & 12,2 & 43,3 & 71,8 \\
\hline 13-122 / B.I & 0,21 & 0,2 & 50,0 & 0,0 & 0,0 & 0,2 & 50,0 & 99,6 \\
\hline B.I -Total & 2,31 & 17,3 & 39,6 & 0,0 & 0,0 & 26,4 & 60,4 & 56,3 \\
\hline
\end{tabular}

M.M: matéria mineral, S/MM: sem matéria mineral; Esp.: espessura, B.B: Barro Branco, I: Irapuá, A: Camada A, B.S: Bonito Superior, B.I: Bonito Inferior, P.B.S: Pré-Bonito Superior, P.B.I: Pré-Bonito Inferior 
foi maior que $300^{\circ} \mathrm{C}$, pois a liptinita sofre desvolatilização em temperaturas maiores que $300^{\circ} \mathrm{C}$. A inertinita varia de $24,9 \%$, na camada Irapuá, até 98,5\%, na camada Bonito Inferior.

O diagrama ternário (Fig. 7) dos grupos de macerais mostra a composição petrográfica das camadas de carvão nos três furos estudados. Pode-se observar que as amostras da camada Barro Branco, que está no topo do pacote carbonoso, apresentam variação interna na quantidade de vitrinita e inertinita (Fig. 7). As amostras do topo da camada mostram alto conteúdo de vitrinita e baixo conteúdo de inertinita. Já as amostras que estão mais perto da base da camada apresentam conteúdo menor de vitrinita e maior de inertinita. Conforme Kalkreuth et al. (2010), a camada Barro Branco foi depositada em um trato de sistemas transgressivo (Fig. 3A), e, segundo Diessel (1992), o carvão formado durante a transgressão sofre mudanças de condiçóes ambientais relativamente secas para condiçóes mais úmidas em resposta à subida do nível do lençol freático devido ao aumento do nível do mar. Esse ambiente mais úmido forma pântanos, que são mais favoráveis à acumulaçáo de matéria orgânica, o que resultará em condiçóes propícias para a formação de carvão mais enriquecido em vitrinita.

As amostras da camada Bonito Inferior também apresentam uma variação interna no conteúdo de vitrinita e inertinita, porém, a quantidade de vitrinita aumenta do topo para a base (Fig. 7), enquanto o conteúdo de inertinita apresenta aumento significativo nas amostras de topo da camada. Segundo Kalkreuth et al. (2010), essa camada foi depositada em um trato de sistema de nível alto (Fig. 3A) e, com isso, a oxidaçáo da matéria orgânica favoreceu a formação de inertinita no topo da camada.

Nas amostras da camada Pré-Bonito Superior observamos uma grande variação no conteúdo de vitrinita (Fig. 7), sendo que as amostras da base da camada apresentam alto conteúdo de vitrinita e pouca inertinita, enquanto as amostras do topo apresentam baixo conteúdo de vitrinita e alto conteúdo de inertinita (Tab.3). Uma explicação para essa variação é o ambiente deposicional, pois, segundo Kalkreuth et al. (2010), a camada Pré-Bonito Superior foi depositada em um trato de sistemas transgressivo (Fig. 3A), enquanto as camadas acima destas foram depositadas em ambiente de trato de sistemas de nível alto (camadas Bonito Inferior e Superior) (Fig. 3A). Portanto, o topo da camada Pré-Bonito Superior foi afetada pela exposição ocasional e oxidação, devido à oscilação do nível de água dentro do pântano causada pela regressão e descida do nível do mar. Isso gerou enriquecimento no conteúdo de inertinita no topo da camada (Diessel 1992).

No diagrama ternário da Figura 8 foram plotados os valores da composição maceral por camada para os três furos. No furo CBM-SC-2012 foi coletada somente uma amostra da camada Barro Branco, e por isso não foi possível calcular

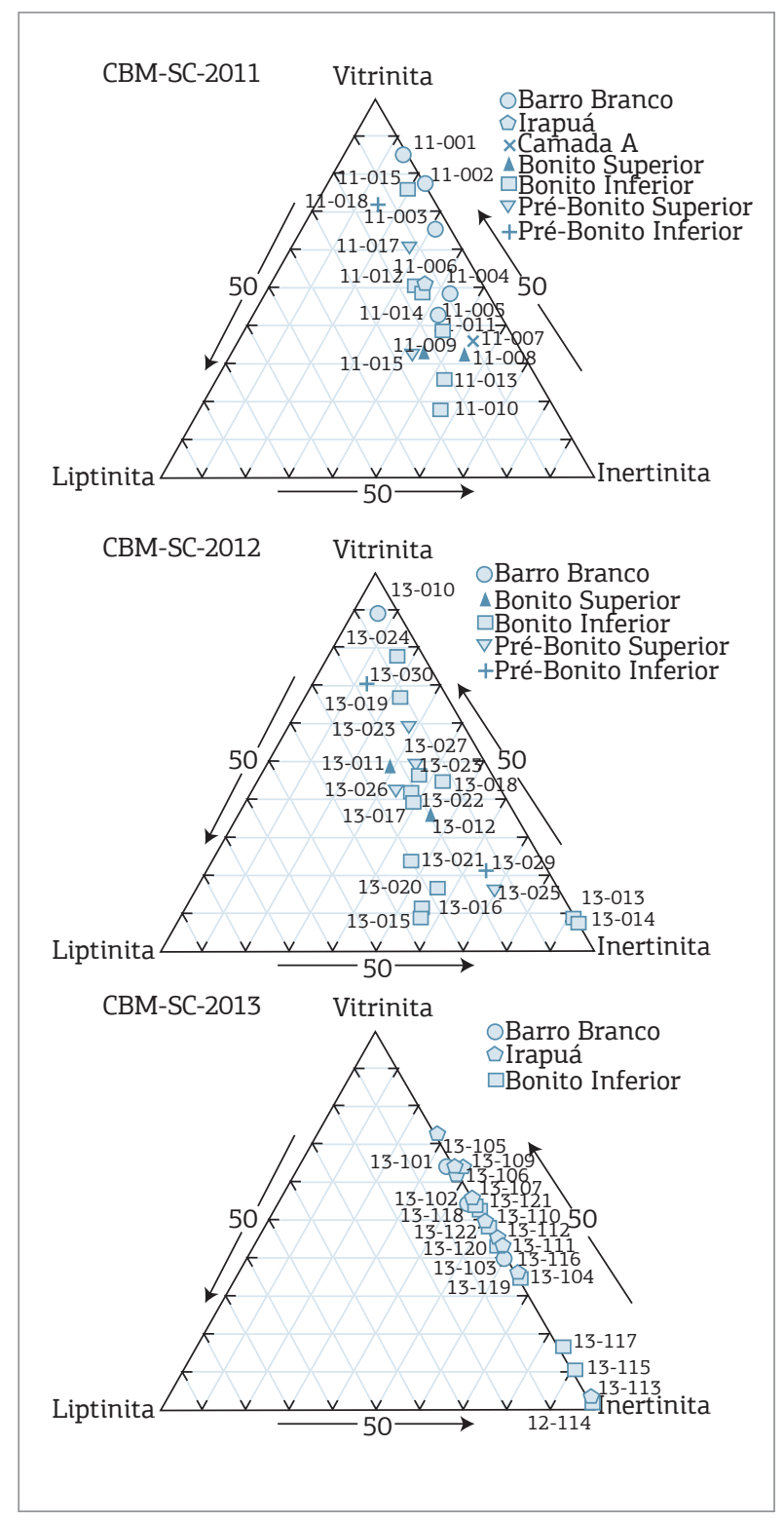

Figura 7. Diagrama ternário mostrando a composição petrográfica dos grupos de macerais (sem matéria mineral) das amostras das camadas de carvão dos três furos.

uma média composicional por camada. Essa amostra é do topo da camada, o que explica o alto conteúdo de vitrinita quando comparado com a média dos outros dois furos. A camada Pré-Bonito Inferior também mostrou grande variação no conteúdo de vitrinita entre os furos CBM-SC-2011 e CBM-SC-2012.

Incluindo a matéria mineral nos resultados das análises petrográficas, no furo CBM-SC-2011 a vitrinita apresenta uma variação de 14 até $66 \%$ (Tab. 3). A liptinita varia de 0 até $18,4 \%$; a inertinita varia de 11,8 até $42,4 \%$; e a matéria mineral varia de 7 até 44,2\%. Já no furo CBM-SC-2012, a vitrinita apresenta variação de 0,4 até $65,4 \%$; a liptinita varia 
de 0 até $21,6 \%$; a inertinita varia de 2,8 até 34,2\%; e a matéria mineral varia de 27,2 até $96,0 \%$. No furo CBM-SC-2013 a vitrinita varia de 0,2 até $63,8 \%$; a liptinita só está presente na camada Barro Branco e varia de 0,2 até 1,8\%; a inertinita varia de 0,2 até $40,4 \%$; e a matéria mineral varia de 15 até $99,6 \%$. Nos três furos observou-se a predominância de colotelinita, seguida de colodetrinita e vitrodetrinita, no grupo da vitrinita, esporinita e liptodetrinita, no grupo da liptinita, com exceção do furo CBM-SC-2013, que apresentou raras esporinitas na camada Barro Branco. No grupo da inertinita houve predominância de inertodetrinita, seguida de semifusinita e fusinita. Já na matéria mineral prevalece a argila, seguida de pirita, e apresenta predominâncias diferentes na

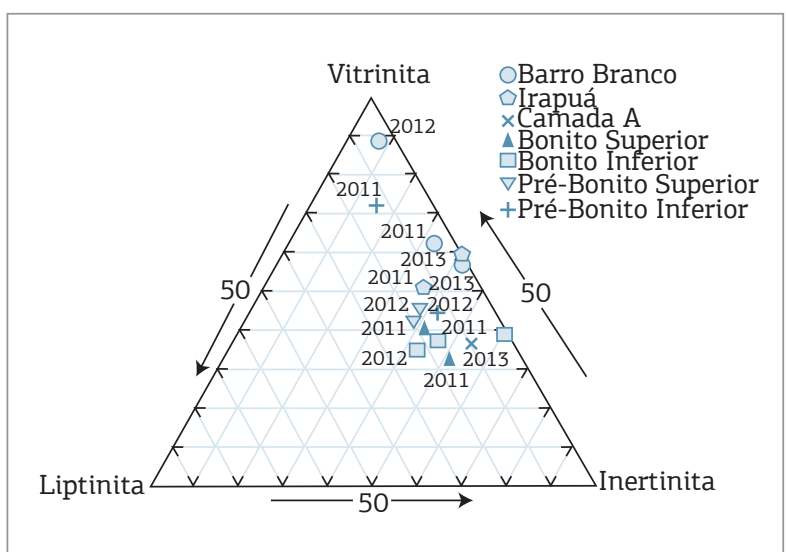

Figura 8. Diagrama ternário mostrando a composição petrográfica dos grupos de macerais (sem matéria mineral) das camadas totais de carvão dos três furos. quantidade de quartzo e carbonato em cada furo. A Fig. 9 mostra a variaçáo composicional das amostras dentro da camada de carvão nos três furos em relação ao posicionamento estratigráfico das mesmas.

Conforme demonstrado na Fig. 9, o conteúdo de vitrinita da camada Barro Branco diminui conforme o conteúdo de inertinita aumenta. Na camada Irapuá, o conteúdo de vitrinita diminui conforme o conteúdo de matéria mineral aumenta. Na camada Bonito Inferior observa-se o aumento no conteúdo de vitrinita em direção à base da camada, enquanto o conteúdo de inertinita diminui.

\section{Análise Imediata}

O percentual de cinzas das camadas de carvão analisadas mostrou valores de 34,93 a 65,70\% (Tab. 4), sendo que o menor valor corresponde à camada Barro Branco, e o maior valor, à Camada $\mathrm{A}$.

Quanto ao percentual de umidade das amostras como recebidas, a camada Barro Branco mostrou o menor valor $(2,20 \%)$, enquanto a camada Bonito Inferior apresentou o maior valor $(3,37 \%)$.

A matéria volátil varia de 12,22 a 27,03\% (Tab. 4), sendo que a camada Bonito Inferior apresenta o menor valor, e a camada Barro Branco, o maior valor. Quando recalculadas em uma base seca e livre de cinzas (d.a.f - dry ash free), o percentual de matéria volátil variou de 30,83 a 54,07\%, sendo que a camada que apresentou o menor valor foi a Bonito Superior, e a Irapuá apresentou o maior valor. A análise de carbono fixo indicou uma variação de 14,40 a $43,43 \%$ em peso, com a camada A apresentando o menor valor.

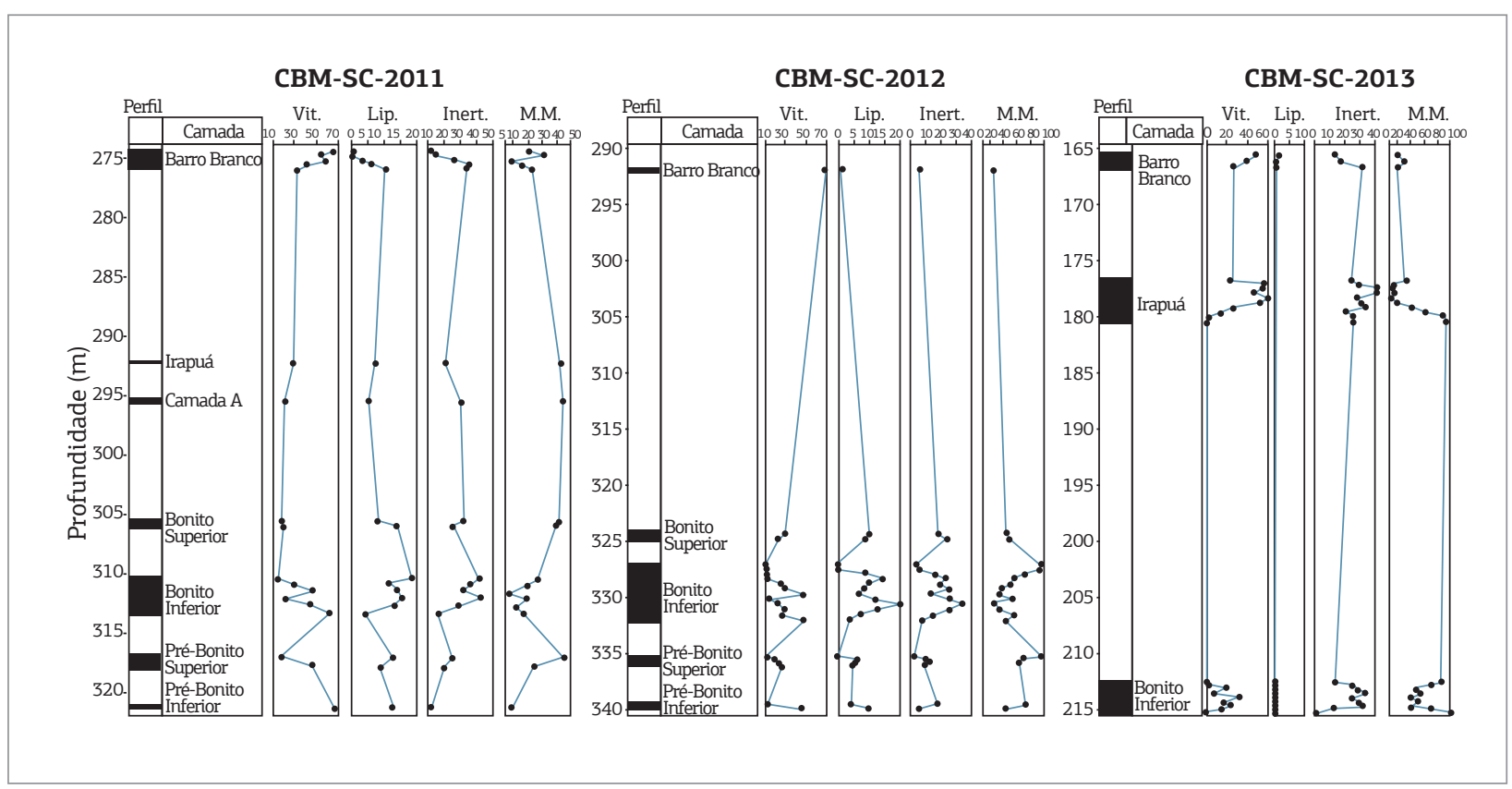

Figura 9. Perfil esquemático mostrando a distribuição dos grupos de macerais e matéria mineral. 
Tabela 4. Resultados da análise imediata e poder calorífico superior por camada.

\begin{tabular}{|c|c|c|c|c|c|c|c|c|}
\hline Camada & Esp.(m) & $\mathrm{Cz}(\%)$ & $\begin{array}{c}\text { Umd. } \\
(\%)\end{array}$ & $\operatorname{MV}(\%)$ & MV(d.a.f) & CF(\%) & $\begin{array}{c}\text { PCS } \\
\text { (cal/g) }\end{array}$ & $\begin{array}{c}\text { PCS (cal/g) } \\
\text { (d.a.f) }\end{array}$ \\
\hline \multicolumn{9}{|l|}{ CBM-SC-2011 } \\
\hline Barro Branco & 1,10 & 34,93 & 2,20 & 27,03 & 41,63 & 35,80 & 5074,8 & 7971,0 \\
\hline Irapuá & 0,12 & 61,90 & 3,00 & 20,60 & 54,07 & 14,50 & 2074,0 & 5611,9 \\
\hline Camada A & 0,36 & 65,70 & 2,80 & 17,10 & 49,85 & 14,40 & 1858,0 & 5573,0 \\
\hline Bonito Superior & 0,49 & 58,06 & 2,40 & 16,12 & 38,40 & 23,41 & 2957,5 & 7229,0 \\
\hline Bonito Inferior & 2,13 & 42,00 & 2,30 & 21,79 & 37,50 & 33,91 & 4377,2 & 7705,3 \\
\hline Pré-Bonito Superior & 1,02 & 59,90 & 2,70 & 15,38 & 38,60 & 21,94 & 2816,1 & 7097,5 \\
\hline Pré-Bonito Inferior & 0,16 & 41,20 & 2,60 & 22,50 & 38,27 & 33,70 & 4731,0 & 8260,7 \\
\hline \multicolumn{9}{|l|}{ CBM-SC-2012 } \\
\hline Barro Branco & 0,20 & 57,53 & 2,70 & 15,50 & 36,49 & 24,27 & 2667,0 & 6453,6 \\
\hline Bonito Superior & 0,43 & 58,23 & 2,46 & 12,88 & 30,83 & 30,83 & 3129,8 & 7682,2 \\
\hline Bonito Inferior & 2,87 & 62,02 & 3,37 & 17,69 & 39,69 & 31,90 & 3898,3 & 8184,0 \\
\hline Pré-Bonito Superior & 1,26 & 65,04 & 3.05 & 12,52 & 35,20 & 43,43 & 2528,8 & 7222,5 \\
\hline Pré-Bonito Inferior & 0,64 & 60,69 & 2,73 & 15,33 & 38,10 & 21,25 & 2450,7 & 6141,1 \\
\hline \multicolumn{9}{|l|}{ CBM-SC-2013 } \\
\hline Barro Branco & 1,04 & 48,12 & 2,68 & 17,42 & 33,53 & 31,78 & 3937,3 & 7795,1 \\
\hline Irapuá & 3,00 & 49,36 & 2,86 & 16,66 & 31,41 & 42,80 & 4906,9 & 8343,3 \\
\hline Bonito Inferior & 2,31 & 63,17 & 2,97 & 12,22 & 31,59 & 30.74 & 3282,8 & 7489,2 \\
\hline
\end{tabular}

Cz (\%) - cinza; Umd (\%) - percentual de umidade em amostras como recebidas; MV (\%): matéria volátil; MV(d.a.f): matéria volátil dry ash free (seco e livre de cinzas); CF: carbono fixo; PCS: poder calorífico superior

Os resultados dos teores de cinzas das amostras de carvão nas camadas estudadas nos três furos estáo expostos na Fig. 10, e mostraram que segundo a norma internacional da Comissão Econômica da Europa para as Naçôes Unidas, 33,3\% das amostras do furo CBM-SC-2011 são classificadas como rocha carbonosa, enquanto $66,6 \%$ são classificadas como carvão de categoria inferior e muito inferior. No furo CBM-SC-2012, $76,2 \%$ das amostras entram na categoria de rocha carbonosa, enquanto $23,8 \%$ das amostras são classificadas como carvão de categoria muito inferior. Já no furo CBM-SC-2013, 54,5\% das amostras se mostram como rocha carbonosa e $45,5 \%$ das amostras se enquadram nas categorias de carvão inferior e muito inferior.

\section{Poder Calorífico}

Os resultados de poder calorífico superior variaram de 1858,0 a $5075,8 \mathrm{cal} / \mathrm{g}$, sendo que a camada A foi a que teve o menor valor, e a camada Barro Branco a que obteve o maior valor, o que pode estar relacionado ao baixo teor de cinza presente na camada, conforme Tab. 4. Quando recalculado para uma base seca e livre de cinzas (d.a.f), obtevese resultados variando de 5573,0 a 8343,3 cal/g (Tab. 4).
O gráfico da Fig. 11 mostra que existe uma relação muito clara entre o teor de cinzas e o poder calorífico superior para os três furos.

\section{Análise Elementar}

Conforme os resultados da análise elementar da Tab. 5 , no furo CBM-SC-2011 o carbono apresenta uma variação de 23,09 até 52,76\%; o hidrogênio varia de 1,93 a 3,72\%; o enxofre varia de 0,41 a 12,43\%; o oxigênio varia de 1,00 até $25,17 \%$; e o nitrogênio varia de 0,15 até $1,17 \%$. No furo CBM-SC-2012, o carbono varia de 5,09 até 46,03\%; o hidrogênio varia de 0,86 até $3,57 \%$; o enxofre varia de 0,22 até $4,64 \%$; o oxigênio varia 1,01 até $6,99 \%$; e o nitrogênio varia de 0,20 até $1,09 \%$. No furo CBM-SC-2013, o carbono varia de 4,15 até $65,81 \%$; o hidrogênio varia de 0,52 até $3,92 \%$; o enxofre varia de 0,47 até $10,06 \%$; o oxigênio varia de 0,14 até $6,08 \%$; e o nitrogênio varia de 0,16 até $1,15 \%$.

O teor de enxofre das amostras exibiu valores de 0,22 até $12,43 \%$, sendo mais altos nas amostras da camada Barro Branco, o que evidencia os efeitos da transgressáo marinha, demonstrada pelo aumento no teor de enxofre pirítico na 


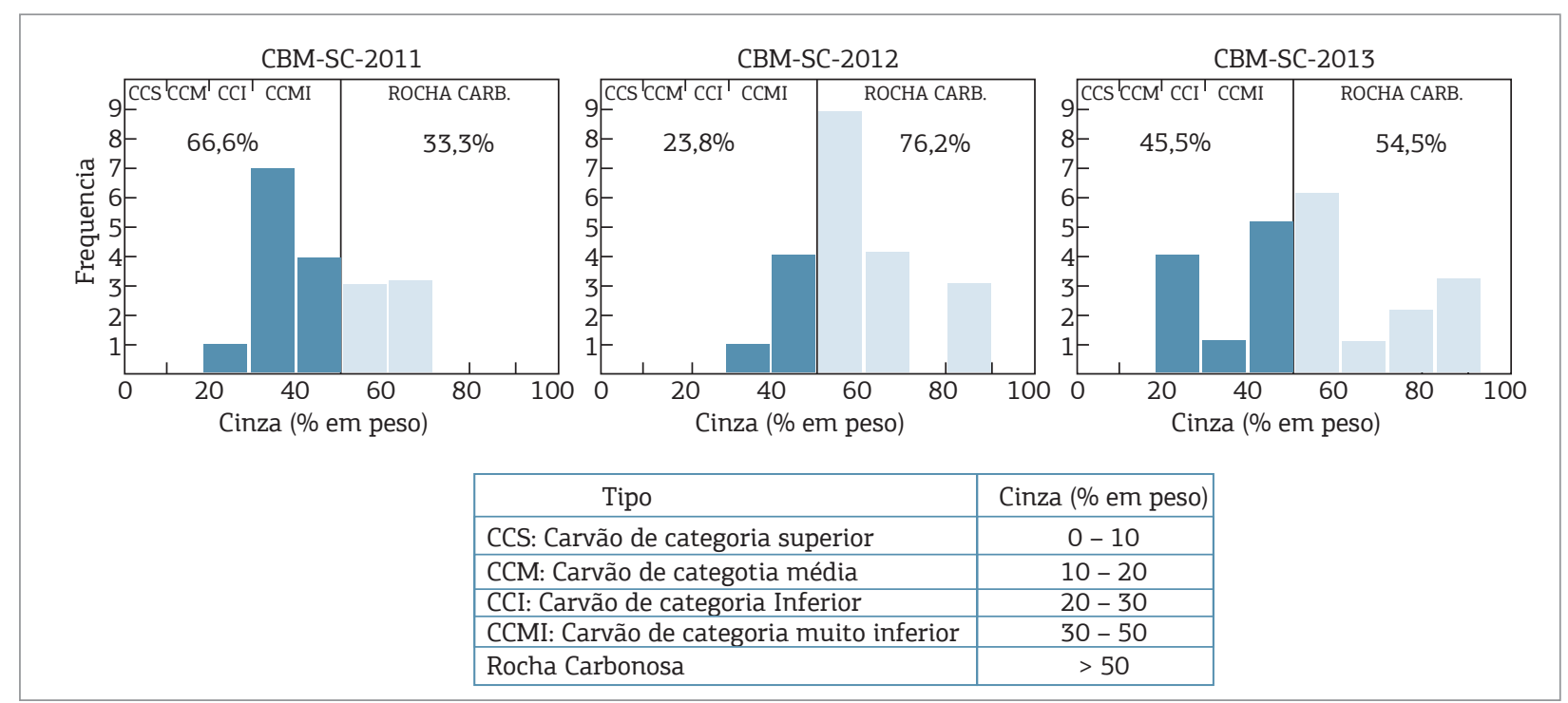

Figura 10. Classificação do carvão segundo o percentual de cinzas. Modificado de International Classification of in-coal seams, 1998.

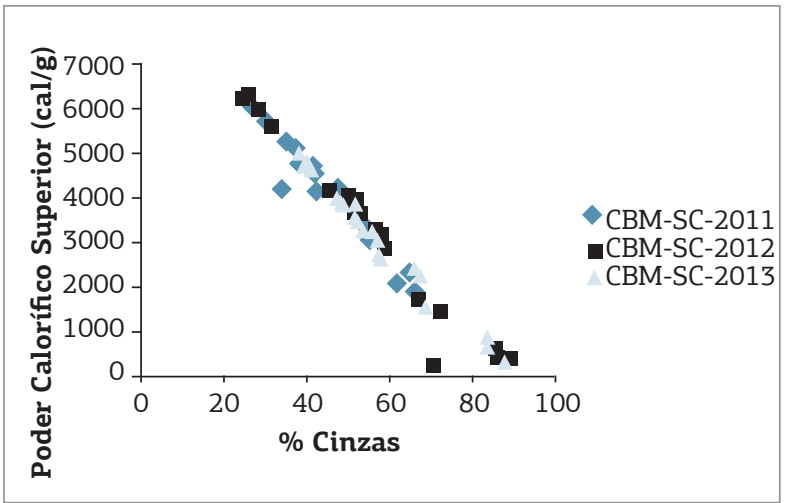

Figura 11. Gráfico dos valores de poder calorífico superior relacionado ao conteúdo de cinzas.

parte superior da camada. Segundo Diessel (1992), altos conteúdos de pirita têm sido uma das características mais comuns nos carvôes com influência marinha. Conforme Berner et al. (1985) e Casagrande (1987), o $\mathrm{H}_{2} \mathrm{~S}$ formado pela reduçáo de bactérias dos sulfatos contidos na água do mar reage com a matéria orgânica para produzir enxofre orgânico ou ferro ferroso, o que resulta na precipitação singenética de Fe-sulfetos ou de pirita.

\section{Características Petrográficas e Químicas das Camadas de Carvão e o Potencial de Gás Associado}

Quando analisamos as propriedades do carvão para avaliar o potencial para a geração de gás, observamos que, de acordo com o rank obtido (betuminoso alto volátil - betuminoso médio volátil), possivelmente tenha havido geração de gás (Karweil 1969). Conforme esse estudo, o gás começa a ser gerado quando o carváo atinge um rank betuminoso alto volátil (em uma temperatura de aproximadamente $80^{\circ} \mathrm{C}$ e reflectância da vitrinita de 0,70 Rrandom(\%)); quanto maior o rank, maior o volume de gás gerado.

Segundo Lamberson (1993), em estudos realizados em amostras de uma sequência de litotipos caracterizada pela diferença no conteúdo de vitrinita, demonstrou-se que a capacidade de adsorção é controlada pelo conteúdo de vitrinita nas camadas de carvão. A porosidade da vitrinita é caracterizada predominantemente por microporos, enquanto a inertinita apresenta mais mesoporos e macroporos. A vitrinita com maior quantidade de microporos apresenta uma área superficial maior do que partículas com mesoporos e macroporos (Thomas \& Damberger 1976), portanto, camadas que apresentam alto conteúdo de vitrinita apresentarão as maiores quantidades de gás adsorvido em seus microporos (Lamberson 1993).

De acordo com as análises realizadas nas amostras de carvão da jazida Sul Catarinense, há um predomínio no conteúdo de vitrinita em relação à inertinita e à liptinita nas camadas de carvão estudadas, sugerindo condiçôes favoráveis para a geração de gás, principalmente na camada Barro Branco, que apresentou o maior conteúdo de vitrinita.

De acordo com o conteúdo de cinzas obtido e a composição maceral, a camada Barro Branco é a que tem maiores chances de ter gerado gás, nos três furos, pois apresenta baixo teor de cinzas e alto conteúdo de vitrinita. Já no furo CBM-SC-2013, a camada Irapuá também apresentou os parâmetros necessários para a geração de gás, pois apresenta o rank necessário, significativo conteúdo de vitrinita e baixo conteúdo de cinzas. A camada Bonito possui menos 
Tabela 5. Resultados da análise elementar.

\begin{tabular}{|c|c|c|c|c|c|c|}
\hline \multicolumn{7}{|c|}{ CBM-SC-2011 } \\
\hline Amostra/ Camada & $\mathrm{C} \%$ & $\mathbf{H} \%$ & S\% & $0 \%$ & $\mathbf{N} \%$ & Cinzas $\%$ \\
\hline 11-001 / B.B & 46,33 & 3,72 & 10,42 & 2,06 & 1,17 & 36,30 \\
\hline 11-002 / B.B & 40,97 & 3,25 & 12,43 & 5,68 & 0,96 & 36,70 \\
\hline 11-003 / B.B & 52,76 & 3,74 & 8,48 & 6,71 & 1,12 & 27,20 \\
\hline 11-004 / B.B & 48,72 & 3,55 & 0,76 & 7,15 & 1,02 & 38,80 \\
\hline 11-005 / B.B & 35,58 & 2,89 & 1,03 & 25,17 & 0,73 & 34,60 \\
\hline $11-006$ / I & 25,53 & 2,64 & 1,03 & 8,34 & 0,57 & 61,90 \\
\hline $11-007$ / A & 23,09 & 2,22 & 0,68 & 8,16 & 0,15 & 65,70 \\
\hline 11-008 / B.S & 34,86 & 2,27 & 0,86 & 5,47 & 0,24 & 56,30 \\
\hline 11-009 / B.S & 31,01 & 2,11 & 0,41 & 6,35 & 0,22 & 59,90 \\
\hline 11-010 / B.I & 37,27 & 2,48 & 1,33 & 5,19 & 0,33 & 53,40 \\
\hline 11-011 / B.I & 52,87 & 3,36 & 1,32 & 3,66 & 0,69 & 38,10 \\
\hline 11-012 / B.I & 53,67 & 3,46 & 2,09 & 9,89 & 0,69 & 30,20 \\
\hline 11-013 / B.I & 46,99 & 2,90 & 1,47 & 5,87 & 0,47 & 42,30 \\
\hline 11-014 / B.I & 50,16 & 3,18 & 1,66 & 2,41 & 0,69 & 41,90 \\
\hline 11-015 / B.I & 46,68 & 3,00 & 2,86 & 12,07 & 0,69 & 34,70 \\
\hline 11-016 / P.B.S & 26,06 & 1,93 & 1,46 & 4,92 & 0,52 & 65,10 \\
\hline 11-017 / P.B.S & 43,73 & 2,88 & 0,94 & 3,96 & 0,88 & 47,60 \\
\hline 11-018 / P.B.I & 51,23 & 3,32 & 2,25 & 1,00 & 1,00 & 41,20 \\
\hline \multicolumn{7}{|c|}{ CBM-SC-2012 } \\
\hline Amostra/ Camada & $\mathrm{C} \%$ & $\mathbf{H} \%$ & S\% & $0 \%$ & $\mathbf{N} \%$ & Cinzas $\%$ \\
\hline 13-010 / B.B & 31,80 & 2,22 & 4,64 & 3,03 & 0,79 & 57,53 \\
\hline 13-011 / B.S & 34,18 & 2,00 & 0,82 & 4,62 & 0,62 & 57,75 \\
\hline 13-012 / B.S & 29,85 & 1,61 & 4,49 & 4,99 & 0,51 & 58,54 \\
\hline 13-013 / B.I & 5,09 & 0,86 & 0,22 & 6,17 & 0,16 & 87,50 \\
\hline 13-014 / B.I & 8,17 & 1,04 & 0,30 & 6,99 & 0,20 & 83,30 \\
\hline 13-015 / B.I & 25,79 & 1,80 & 1,33 & 5,28 & 0,45 & 65,34 \\
\hline 13-016 / B.I & 36,45 & 2,42 & 1,42 & 3,93 & 0,65 & 55,12 \\
\hline 13-017 / B.I & 38,17 & 2,51 & 1,61 & 3,08 & 0,65 & 53,98 \\
\hline 13-018 / B.I & 42,59 & 2,79 & 2,30 & 4,76 & 0,80 & 46,77 \\
\hline 13-019 / B.I & 40,97 & 2,83 & 2,20 & 1,01 & 0,79 & 52,19 \\
\hline 13-020 / B.I & 42,78 & 2,66 & 1,12 & 4,49 & 0,64 & 48,30 \\
\hline 13-021 / B.I & 50,66 & 3,03 & 0,96 & 3,36 & 0,74 & 41,25 \\
\hline 13-022 / B.I & 51,66 & 3,24 & 2,99 & 1,39 & 0,80 & 39,92 \\
\hline 13-023 / B.I & 34,73 & 2,34 & 1,51 & 3,26 & 0,67 & 57,50 \\
\hline 13-024 / B.I & 46,03 & 3,57 & 1,65 & 7,55 & 1,09 & 40,10 \\
\hline 13-025 / P.B.S & 9,15 & 1,00 & 1,08 & 4,88 & 0,24 & 83,65 \\
\hline 13-026 / P.B.S & 25,37 & 1,82 & 2,28 & 2,17 & 0,56 & 67,79 \\
\hline 13-027 / P.B.S & 26,99 & 1,87 & 1,50 & 3,60 & 0,61 & 65,44 \\
\hline 13-028 / P.B.S & 40,02 & 2,52 & 2,00 & 1,41 & 1,01 & 53,04 \\
\hline 13-029 / P.B.I & 21,98 & 1,53 & 3,64 & 3,79 & 0,50 & 68,56 \\
\hline 13-030 / P.B.I & 37,56 & 2,49 & 3,14 & 4,69 & 0,92 & 51,20 \\
\hline
\end{tabular}


Tabela 5. Continuação

\begin{tabular}{|c|c|c|c|c|c|c|}
\hline \multicolumn{7}{|c|}{ CBM-SC-2013 } \\
\hline Amostra/ Camada & $\mathrm{C} \%$ & $\mathrm{H} \%$ & $\mathrm{~S} \%$ & $0 \%$ & N\% & Cinzas $\%$ \\
\hline 13-101 / B.B & 38,30 & 2,50 & 10,06 & 0,82 & 0,72 & 47,60 \\
\hline 13-102 / B.B & 40,04 & 2,73 & 9,60 & 0,94 & 0,78 & 45,91 \\
\hline 13-103 / B.B & 40,45 & 2,87 & 0,96 & 2,90 & 0,74 & 52,09 \\
\hline 13-104 / I & 40,94 & 2,66 & 1,81 & 4,63 & 0,71 & 49,26 \\
\hline 13-105 / I & 64,17 & 3,92 & 1,87 & 2,73 & 1,13 & 26,18 \\
\hline $13-106$ / I & 65,81 & 3,89 & 1,58 & 1,78 & 1,14 & 25,81 \\
\hline 13-107 / I & 62,16 & 3,64 & 1,62 & 2,88 & 1,08 & 28,63 \\
\hline $13-108$ / I & 62,84 & 3,69 & 4,77 & 1,59 & 1,15 & 25,97 \\
\hline 13-109 / I & 58,90 & 3,46 & 1,84 & 3,09 & 1,01 & 31,69 \\
\hline $13-110$ / I & 32,63 & 2,41 & 1,32 & 4,29 & 0,60 & 58,76 \\
\hline 13-111 / I & 23,76 & 1,96 & 1,94 & 5,49 & 0,45 & 66,40 \\
\hline 13-112 / I & 4,15 & 0,61 & 2,25 & 4,60 & 0,16 & 88,23 \\
\hline $13-113$ / I & 5,96 & 0,78 & 3,76 & 4,62 & 0,18 & 84,70 \\
\hline 13-114 / B.I & 6,97 & 1,03 & 0,47 & 6,08 & 0,19 & 85,26 \\
\hline 13-115 / B.I & 20,74 & 1,46 & 0,92 & 4,19 & 0,42 & 72,27 \\
\hline 13-116 / B.I & 41,86 & 2,43 & 1,55 & 1,58 & 0,82 & 51,76 \\
\hline 13-117 / B.I & 40,76 & 2,28 & 2,17 & 1,34 & 0,67 & 52,78 \\
\hline 13-118 / B.I & 35,78 & 2,09 & 2,27 & 1,67 & 0,61 & 57,57 \\
\hline 13-119 / B.I & 41,06 & 2,28 & 5,19 & 1,25 & 0,66 & 49,55 \\
\hline 13-120 / B.I & 42,20 & 2,39 & 4,63 & 0,51 & 0,71 & 49,56 \\
\hline 13-121 / B.I & 30,92 & 2,05 & 8,06 & 0,14 & 0,66 & 58,17 \\
\hline 13-122 / B.I & 6,55 & 0,52 & 10,00 & 2,25 & 0,20 & 70,47 \\
\hline
\end{tabular}

onde N: nitrogênio, C: carbono, H: hidrogênio, S: enxofre, O: oxigênio, expressos na forma de \% em peso

potencial para gerar gás devido ao seu alto conteúdo de matéria mineral.

As camadas de carvão analisadas no presente estudo têm características petrográficas e químicas semelhantes às camadas da jazida Santa Terezinha (RS), onde estudos de Kalkreuth et al. $(2008,2013)$ mostram um volume significativo de gás natural associado às camadas de carváo.

\section{CONCLUSÕES}

Diversos fatores geológicos contribuem e influenciam diretamente para que uma sucessão carbonosa tenha potencial de geração de CBM. A geração do metano está relacionada diretamente com o grau de carbonificação da matéria orgânica, que, por sua vez, dependerá das condiçôes de temperatura e pressão às quais a sucessão estratigráfica foi submetida (Murray 1991 apud Bustin \& Clarkson 1998). O metano gerado termicamente nos carvóes começa a se formar a partir do rank betuminoso alto volátil (com refletância da vitrinita entre 0,6 e 0,7\% Ro) (Karweil 1956). A capacidade de armazenamento de metano em carvão é igualmente influenciada pela classificação do carvão (conteúdo de matéria mineral versus conteúdo de matéria orgânica), tipo de carvão (macerais) e rank do carvão, mas é também afetada por outros parâmetros, como profundidade do reservatório, temperatura, umidade e arranjo 
estrutural (Eddy et al. 1982; Kaiser et al. 1992; Dawson \& Kalkreuth 1994).

As análises petrográficas e químicas e a interpretação dos resultados obtidos no presente estudo indicaram que o carvão da Formação Rio Bonito da jazida Sul Catarinense tem as características necessárias para a geração de gás, principalmente as camadas Barro Branco e Irapuá, por apresentarem o rank necessário para a geração de gás, alto conteúdo de vitrinita e baixo teor de matéria mineral, enquanto a camada Bonito apresenta baixo potencial devido ao alto conteúdo de matéria mineral.

Atividades futuras deste estudo incluem a determinação de características de desorção e adsorção das mesmas amostras das camadas de carvão da jazida Sul Catarinense utilizadas neste trabalho, além da determinação da porosidade, para determinar se houve geração de gás, se ele ficou armazenado ou se houve escape para atmosfera por falta de soterramento (pressão), além de determinar o grau de saturação em metano da jazida.

\section{AGRADECIMENTOS}

Ao CNPq, pelo suporte financeiro através do Edital 20 (processo 551239/2010-7), pela bolsa de produtividade em pesquisa (CNPq 301080/2010-0) e pela bolsa de mestrado - GM (processo 551239/2010-7).

À empresa Maracajá Mineração Ltda. e à Carbonífera Criciúma, por disponibilizarem as amostras de carvão das sondagens utilizadas neste trabalho, que faz parte da dissertação de mestrado da autora.

\section{REFERÊNCIAS}

Aramis J., Pereira G., Cruz P.R., Borges L.P. 2003. Recursos Minerais Energéticos: Carvão e Urânio. P. In: Bizzi, L.A., Schobbenhaus, C., Vidotti, R.M., Gonçalves, J.H. (eds). 2003. Geologia, Tectônica e Recursos Minerais do Brasil. Brasília, CPRM, p. 577-601.

ASTM. 1991. Annual Book of ASTM Standards. Sec 05.05. Standard Test Methods for Moisture in the Analysis Sample of Coal and Coke. ASTM, D 3173-87, Philadelphia, PA, p. 324-325.

ASTM.1991, Annual Book of ASTM Standards. Sec. 05.05 Standard Test Method for Ash in the Analysis Sample of Coal and Coke from Coal. ASTM, D 3174-89, Philadelphia, PA, p.326-328.

ASTM.1991, Annual Book of ASTM Standards. Sec 05.05. Standard Test Method for Volatile Matter in the Analysis Sample of Coal and Coke.ASTM, D 3175-89a, Philadelphia, PA, p.329-331.

ASTM.1991, Annual Book of ASTM Standards. Sec 05.05. Standard Test Method for Gross Calorific Value of Coal and Coke by the Adiabatic Bomb Calorimeter. ASTM, D 2015-91, Philadelphia, PA, p.266-273.

ASTM D 5373-93. 1997. Standard Test Methods for Instrumental Determination of Carbon, Hydrogen and Nitrogen in laboratory samples of coal and coke. In: 1997 Annual Book of ASTM standards, section 5, Petroleum Products, Lubricants and fossil fuels. Vol. 05.05. Gaseous fuels: coal and coke. p. 495-462.

ASTM D2013/D2013M-12.2012. Standard Practice for Preparing coal samples for analysis. ASTM International, West Conshohocken, PA. http://dx.doi.org/10.1520/D2013_D2013M-12www.astm.org.

Berner R.A., De Leeuw J.W., Spiro B., Murchison D.G., Eglinton G. 1985. Sulphate reduction, organic matter decomposition and pyrite formation. Philosophical Transactions of the Royal Society of London, A315:25-38.

Bustin R.M., Clarkson C.R. 1998. Geological controls on coalbed methane reservoirs capacity and gas content. International Journal of Coal Geology, 38(1-2):3-26
Casagrande D.J. 1987. Sulphur in peat and coal. In: Scott, A.C (ed). Coal and coal bearing strata: Recent advances.Geological Society Special Publication, 32:87-105

Dawson M., Kalkreuth W. 1994. Coal rank and coal bed methane potential of Cretaceous/Tertiary coals in the Canadian Rocky Mountain Foothills and Foreland: 1. Hinton and Grande Cache areas, Alberta. Bulletin of Canadian Petroleum Geology, 42(4):544-561.

Diessel C. 1965. Correlation of macro-and micropetrography of some New South Wales coals.In: Proceedings $8^{\text {th }}$ Commen wealth Mining and Metallurgical Congress, vol.6, p. 669-677.

Diessel C. 1992. Coal-Bearing Depositional Systems. Springer Verlag. Berlim. 721p.

Eddy G., Rightmire C., Byren C. 1982. Relationship of methane content with coal rank and depth: theoretical versus observed. In: Proceedings of Unconventional Gas Recovery Symposium, Pittsburgh, Pennsylvania, SPE/DOE 10800, p. 117-122.

Filho A.T., Mizusaki A.M.P., Antonioli L. 2008. Magmatismo nas bacias sedimentares brasileiras e sua influência ma geologia do petróleo. Revista Brasileira de Geociências, 38(2):128-137.

Goodarzi F., Gentzis T., Snowdon L., Bustin R., Labonte M. 1993. Effect of mineral matrix and seam thickness on reflectance of vitrinite in high to low volatile bituminous coals: an enigma. Marine and Petroleum Geology, 10(2):p.162-171.

Informativo Anual da Indústria Carbonífera. 2000. Ministério de Minas e Energia, Departamento Nacional de Produção Mineral. Brasília, ano XV, 217p.

International Classification of in-seam coals. 1998. Economic Commission for Europe, Committee on Sustainable Energy. Geneva: United Nations, 41p.

ISO-7404/5.2009. Methods for the petrographic analysis of coals. Part 5: Method of determining Microscopically the Reflectance of Vitrinite. International Organization for Standardization.14p. 
ISO-7404/3. 2009. Methods for the petrographic analysis of coals. Part 3. Methods of determining maceral group composition. International Organization for Standardization. 8 p.

Kaiser W., Taylor R., Ambrose W., Scott A., Patchen D. 1992.Geological evaluation of critical production parameters for coal bed methane resources. Quarterly Review of Methane from Coal Seams Technology 9:19-23.

Kalkreuth W., Holz M., Kern M., Burger H., Schauf A., Prissang R., Sousa M.L., Rodrigrez C. 2003.The coalbed methane potential of the Paraná Basin. In:Congresso Brasileiro de Petróleo e Gás, 2, Rio de Janeiro, Anais, p.1-6, CD ROM.

Kalkreuth W., Holz M., Casagrande J., Cruz R., Oliveira T., Kern M., Levandowski J., Rolim S. 2008. O potencial de CoalbedMethane (CBM) na jazida da Santa Terezinha-modelagem 3D e avaliação do poço de exploração CBM001-ST-RS. Revista Brasileira de Geociências, 38(2):3-17

Kalkreuth W.,Holz M., Mexias A., Balbinot M., Levandowski J., Willet J., Finkelman R., Burger H. 2010. Depositional setting, petrology and chemistry of Permian coals from the Paraná Basin: 2. South Santa Catarina Coalfield, Brazil. International Journal of Coal Geology, 84(3-4):213-236

Kalkreuth W., Holz M., Levandowski J., Kern M., Casagrande J.,Weniger P., Krooss B. 2013. The coalbed methane (CBM) potential and $\mathrm{CO}_{2}$ storage capacity of the Santa Terezinha Coalfield, Paraná basin, Brazil - 3D modeling, and coal and carbonaceous shale characteristics and related desorption and adsorption capacities in samples from exploration Borehole CBM001-ST-RS. Energy Exploration \& Exploitation, 31(4).

Karweil J. 1956. Die Metamorphose der Kohlenvom Stabdpunkt der physikalischen Chemie. Zur Bewegung der Iranisch-Afghanischen 107:132-139.

Karweil, J. 1969. Actuelle Probleme der Geochemie der kohle. In: Advances in Organic Geochemistry. Oxford: Pergamon Press, p. 59-84

Lamberson M.N., BustinR.M. 1993. Coalbed methane characteristics of Gates Formation Coals, Northeastern British Columbia: Effect of Maceral Composition. The American Association of Petroleum Geologists Bulletin. 77(12):2062-2076.
Leckie DA., Kalkreuth W., Snowdon L.R. 1988. Source rock potential and Thermal Maturity of Lower Cretaceous strata: Monkman Pass Area, British Columbia. The American Association of Petroleum Geologists Bulletin. 72(7),p. 820-838.

Levandowski J.H. 2013. Características petrográficas e geoquímicas das camadas de carvão do poço CBM 001-CL-RS, jazida Chico Lomã, e sua relação com CoalbedMethane associado. Tese de doutorado, Programa de Pós-Graduação em Geociências, Instituto de Geociências, Universidade Federal do Rio Grande do Sul, Porto Alegre. 167p.

Marchioni D., Kalkreuth W. 1991. Coal facies interpretations based on lithotype and maceral variations in Lower Cretaceous (Gates Formation) coals of Western Canada. International Journal of Coal Geology, 18:125-162

Mastalerz M., Drobniak A., Schimmelmann A. 2009. Changes in optical properties chemistry and micropore and mesopore characteristics of bituminous coal at the contact with dikes in the Illinois Basin.International Journal of Coal Geology, 77(3-4):310-319.

Milani E.J. 1997. Evolução tectono-estratigráfica da Bacia do Paraná e seu relacionamento com a geodinâmica Fanerozóica do Gondwana sul-ocidental. Tese de Doutorado, Instituto de Geociências, Universidade Federal do Rio Grande do Sul. Porto Alegre. 225 p.

Milani E.J., Melo J.H.G., Souza P.A., Fernandes L.A., França A.B. 2007. Bacia do Paraná. Boletim de Geociências da Petrobrás, 15(2):265-287.

Murray D.K. 1991.Coalbed methane; natural gas resources from coal seams. In: Peters, D.C. (ed.). Geology in Coal Resource Utilization. United States: Tech Books. p. 97-103.

Stopes M.C. 1919. On the four visible ingredients in banded bituminous coals. Proceeding of the Royal Society. 90(633):470-487.

Thomas J. Damberger H. 1976. Internal surface area, moisture content and porosity of Illinois coals: variations coal rank. Illinois: State Geological Survey, Urbana, Illinois.

Zalán P.V., Wolff S., Conceição J.C.J., Marques A., Astolfi M.A., Vieira I.S., Appi C.J., Zanoto O.A. 1990. Bacia do Paraná. In: Cabaglia, G.P.R. Milani, E.J. (eds.). Origem e evolução das bacias sedimentares. Rio de Janeiro: Petrobrás. p. 135-168

Arquivo digital disponível on-line no site www.sbgeo.org.br 